\title{
Sensorless Control Strategy for Light-duty EVs and Efficiency Loss Evaluation of High Frequency Injection under Standardized Urban Driving Cycles
}

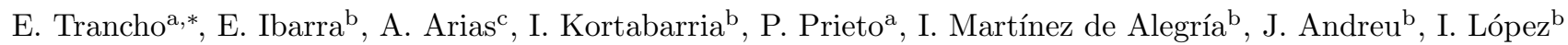 \\ ${ }^{a}$ Tecnalia Research and Innovation, Parque Científico y Tecnológico de Bizkaia, c/ Geldo, Edif. 700, 48160 Derio, Spain \\ ${ }^{b}$ Department of Electronic Technology, UPV/EHU, C. Rafael Moreno Pitxitxi 3, 48013 Bilbao, Spain \\ ${ }^{c}$ Institut d'Organització i Control, Universitat Politècnica de Catalunya, Diagonal, 647, 08028 Barcelona, Spain
}

\author{
Highlights \\ - Full sensorless control proposed for electric vehicle drives \\ - High frequency injection (HFI) successfully combined with Phase Locked Loop (PLL) \\ - Experimental results obtained from a real automotive $51 \mathrm{~kW}$ drive \\ - An accurate simulation model proposed for system power loss estimation \\ - Efficiency of EV sensorless operation tested for standard driving cycles
}

\begin{abstract}
Sensorless control of Electric Vehicle (EV) drives is considered to be an effective approach to improve system reliability and to reduce component costs. In this paper, relevant aspects relating to the sensorless operation of EVs are reported. As an initial contribution, a hybrid sensorless control algorithm is presented that is suitable for a variety of synchronous machines. The proposed method is simple to implement and its relatively low computational cost is a desirable feature for automotive microprocessors with limited computational capabilities. An experimental validation of the proposal is performed on a full-scale automotive grade platform housing a $51 \mathrm{~kW}$ Permanent Magnet assisted Synchronous Reluctance Machine (PM-assisted SynRM). Due to the operational requirements of EVs, both the strategy presented in this paper and other hybrid sensorless control strategies rely on High Frequency Injection (HFI) techniques, to determine the rotor position at standstill and at low speeds. The introduction of additional high frequency perturbations increases the power losses, thereby reducing the overall efficiency of the drive. Hence, a second contribution of this work is a simulation platform for the characterization of power losses in both synchronous machines and a Voltage Source Inverters (VSI). Finally, as a third contribution and considering the central concerns of efficiency and autonomy in EV applications, the impact of power losses are analyzed. The operational requirements of High Frequency Injection (HFI) are experimentally obtained and, using state-of-the-art digital simulation, a detailed loss analysis is performed during real automotive driving cycles. Based on the results, practical considerations are presented in the conclusions relating to EV sensorless control .
\end{abstract}

Keywords: Electric Vehicle, PM-assisted SynRM, efficiency, sensorless, HFI, NEDC

\section{Introduction}

Electric Vehicles (EV) represent an attractive technology in response to such serious environmental and societal issues as fossil fuel dependency, urban pollution and climate change [1-4]. Besides, EVs provide other benefits, as they can be used as additional energy storage systems for future smart grids [5]. According to a number of analysts, the EV market will have a promising future. Some

\footnotetext{
* Corresponding author

Email addresses: elena.trancho@tecnalia.com (E. Trancho), edorta.ibarra@ehu.eus (E. Ibarra), antoni.arias@upc.edu (A. Arias), inigo.kortabarria@ehu.eus (I. Kortabarria), pablo.prieto@tecnalia.com (P. Prieto), inigo.martinezdealegria@ehu.eus (I. Martínez de Alegría), jon.andreu@ehu.eus (J. Andreu), iraide.lopez@ehu.eus (I. López)
}

forecasts expect a global stock of 200 million EV units by 2030 [6]. However, these technologies have higher manufacturing costs than conventional vehicles [7]. As vehicle costs [3], driving ranges $[1,8,9]$, reliability $[10,11]$, and safety [11] are prioritized by consumers, significant research will be required, to increase EV market penetration [12].

The electric machine of an EV is its most relevant component. Synchronous machines with high saliency, such as Interior Permanent Magnet Synchronous Machines (IPMSM) and Permanent Magnet Assisted Synchronous Reluctance Machines (PM-assisted SynRMs) are considered appropriate components for EV applications, due to their reliability, high power density, and high efficiency $[13,14]$. High performance torque control requires accurate and continuous information of the rotor position [15]. 


\begin{tabular}{|c|c|c|c|c|}
\hline \multicolumn{5}{|c|}{$\begin{array}{l}\text { Nomenclature } \\
V_{i}\end{array}$ Voltage amplitude produced by the HFI (V) } \\
\hline \multicolumn{2}{|l|}{$w_{i}$} & $\mathrm{HF}$ perturbation rotation speed $(\mathrm{rad} / \mathrm{s})$ & $V_{c e}$ & Collector-emitter voltage $(\mathrm{V})$ \\
\hline \multicolumn{2}{|l|}{$f_{i}$} & $\mathrm{HF}$ perturbation rotation frequency $(\mathrm{Hz})$ & $\begin{array}{l}V_{c e} \\
V_{c e s}\end{array}$ & Maximum blocking voltage (V) \\
\hline \multicolumn{2}{|l|}{$\omega_{t h}$} & Transition point between HFI and observer (rad/s) & $\begin{array}{l}V_{\text {ces }} \\
V_{\text {ces }}\end{array}$ & Typical collector-emitter voltage (V) \\
\hline \multicolumn{2}{|l|}{$\widehat{\mathbf{e}}_{\alpha \beta}$} & Estimated back-EMF in the $\alpha \beta$ reference frame (V) & $i_{c}$ & Instantaneous collector current $(\mathrm{A})$ \\
\hline \multicolumn{2}{|l|}{$\mathbf{i}_{\alpha \beta}$} & Machine voltages in the $\alpha \beta$ reference frame (V) & $I_{\max }$ & Maximum collector current (A) \\
\hline \multicolumn{2}{|l|}{$\mathbf{v}_{\alpha \beta}$} & Machine currents in the $\alpha \beta$ reference frame (V) & $I_{\text {nom }}$ & Nominal collector current (A) \\
\hline$R_{s}$ & & Stator resistance $(\Omega)$ & $T_{v j, I G B T}$ & IGBT junction temperature $\left({ }^{\circ} \mathrm{C}\right)$ \\
\hline$L_{s}$ & & Stator inductance $(\mathrm{H})$ & $P_{s w, I G B T}$ & IGBT switching losses (W) \\
\hline$L_{d}$ & & Stator inductance in the d-axis $(\mathrm{H})$ & $E_{O N}$ & IGBT turn-on energy losses $(\mathrm{J})$ \\
\hline$L_{q}$ & & Stator inductance in the q-axis $(\mathrm{H})$ & $E_{O F F}$ & IGBT turn-off energy losses $(\mathrm{J})$ \\
\hline$\Psi_{P M}$ & & & $R_{G}$ & Gate resistance $(\Omega)$ \\
\hline$\omega_{e}$ & & Electrical speed $(\mathrm{rad} / \mathrm{s})$ & $C_{D C}$ & DC-link capacitance $(\mathrm{F})$ \\
\hline$\widehat{\omega}_{e}$ & & Estimated electrical speed $(\mathrm{rad} / \mathrm{s})$ & $P_{\text {cond }, D}$ & Diode conduction losses (W) \\
\hline$\theta_{e}$ & & Rotor electrical position (rad) & $V_{F}$ & Diode forward voltage $(\mathrm{V})$ \\
\hline$\widehat{\theta}_{e, P L L}$ & & PLL estimated rotor electrical position (rad) & $i_{F}$ & Diode forward current (A) \\
\hline$\widehat{\theta}_{e, H F I}$ & & HFI estimated rotor electrical position (rad) & $P_{s w, D}$ & Diode switching losses (W) \\
\hline$\widehat{\theta}_{e, H F I}^{\prime}$ & & $\begin{array}{l}\text { HFI estimated rotor electrical position (rad) without consid- } \\
\text { ering polarity }\end{array}$ & $\begin{array}{l}E_{R R} \\
P_{l o s s, i n v}\end{array}$ & $\begin{array}{l}\text { Diode recovery energy losses }(\mathrm{J}) \\
\text { Inverter power losses }(\mathrm{W})\end{array}$ \\
\hline$\Delta_{e}$ & & Angle deviation (rad) & $\omega_{w h e e l}$ & Vehicle wheel speed (rad/s) \\
\hline$P$ & & Rotor pole-pair & $\omega_{d c}$ & Driving cycle speed $(\mathrm{m} / \mathrm{s})$ \\
\hline$P_{N}$ & & Maximum power $(\mathrm{W})$ & $T_{\text {wheel }}$ & Vehicle wheel torque (Nm) \\
\hline$\omega_{m} a x$ & & Maximum speed (rad/s) & $r_{w h e e l}$ & Vehicle wheel radius $(\mathrm{m})$ \\
\hline$R_{F e}$ & & Magnetic resistance $(\Omega)$ & $F_{\text {roll }}$ & Rolling resistance $(\mathrm{N})$ \\
\hline$v_{d}$ & & d-axis voltage $(\mathrm{V})$ & $F_{\text {Aero }}$ & Aerodynamic resistance $(\mathrm{N})$ \\
\hline$v_{q}$ & & q-axis voltage (V) & $F_{\text {Inertia }}$ & Inertia force $(\mathrm{N})$ \\
\hline$v_{d}^{*}$ & & $\mathrm{~d}$-axis reference voltage $(\mathrm{V})$ & $M_{\text {car }}$ & Total vehicle mass $(\mathrm{g})$ \\
\hline$v_{q}^{*}$ & & $\mathrm{q}$-axis reference voltage $(\mathrm{V})$ & $a_{g}$ & Gravity acceleration $(\mathrm{m} / \mathrm{s})$ \\
\hline$i_{d}$ & & d-axis current $(\mathrm{A})$ & $\mu$ & Rolling friction coefficient \\
\hline$i_{q}$ & & $\mathrm{q}$-axis current $(\mathrm{A})$ & $\rho$ & Air density $\left(\mathrm{kg} / \mathrm{m}^{3}\right)$ \\
\hline$i_{d}^{*}$ & & $\mathrm{~d}$-axis reference current $(\mathrm{A})$ & $C_{d}$ & Drag coefficient \\
\hline$i_{q}^{*}$ & & q-axis reference current (A) & $A_{f}$ & Vehicle cross section $\left(\mathrm{m}^{2}\right)$ \\
\hline$\Psi_{d}$ & & $\mathrm{~d}$-axis flux $(\mathrm{Wb})$ & $M_{\text {rot }}$ & Equivalent mass of rotating parts (\%) \\
\hline$\Psi_{q}$ & & q-axis flux (Wb) & $a_{\text {car }}$ & Car acceleration $\left(\mathrm{m} / \mathrm{s}^{2}\right)$ \\
\hline$v_{d, S T}$ & & d-axis Super-twisting voltage $(\mathrm{V})$ & $G R$ & Gear ratio \\
\hline$v_{q, S T}$ & & q-axis Super-twisting voltage (V) & $\eta_{G R}$ & Gear ratio efficiency (\%) \\
\hline$v_{d, e q}$ & & $\mathrm{~d}$-axis equivalent voltage $(\mathrm{V})$ & $T_{\text {trans }}$ & Transmission torque $(\mathrm{Nm})$ \\
\hline$v_{q, e q}$ & & $\mathrm{q}$-axis equivalent voltage $(\mathrm{V})$ & $T_{\text {Idling }}$ & Idling torque $(\mathrm{Nm})$ \\
\hline$c_{d}$ & & $\mathrm{~d}$-axis equivalent voltage regulation parameter & $P_{G T}$ & Idling losses (W) \\
\hline$c_{q}$ & & q-axis equivalent voltage regulation parameter & $E_{\text {batt }}$ & Battery energy $(\mathrm{J})$ \\
\hline$\lambda_{d}$ & & d-axis STA regulation parameter & $\Gamma_{\text {sim }}$ & Simulation factor \\
\hline$\lambda_{q}$ & & $\mathrm{q}$-axis STA regulation parameter & $t_{\text {sim }}$ & Simulation completion time (s) \\
\hline$\Omega_{d}$ & & d-axis STA regulation parameter & $t_{\text {behaviour }}$ & Simulation time $(\mathrm{s})$ \\
\hline$\Omega_{q}$ & & q-axis STA regulation parameter & $E_{\text {loss }, m o t}$ & Motor total energy losses $(\mathrm{J})$ \\
\hline$T_{e m}$ & & Electromagnetic torque $(\mathrm{Nm})$ & $E_{l o s s, C u}$ & Motor copper energy losses $(\mathrm{J})$ \\
\hline$i_{F e, d}$ & & d-axis iron loss current $(\mathrm{A})$ & $E_{l o s s, F e}$ & Motor magnetic energy losses $(\mathrm{J})$ \\
\hline$i_{F e, q}$ & & $\mathrm{q}$-axis iron loss current $(\mathrm{A})$ & $E_{\text {loss }, i n v}$ & Inverter total energy losses $(\mathrm{J})$ \\
\hline$i_{m a g, d}$ & & $\mathrm{~d}$-axis magnetizing current $(\mathrm{A})$ & $E_{\text {loss }, \text { condQ }}$ & IGBT conduction losses $(\mathrm{J})$ \\
\hline$i_{m a g, q}$ & & $\mathrm{q}$-axis magnetizing current $(\mathrm{A})$ & $E_{l o s s, s w Q}$ & IGBT switching losses $(\mathrm{J})$ \\
\hline$P_{L}$ & & Machine power losses (W) & $E_{\text {loss }, \text { condD }}$ & Diode conduction losses $(\mathrm{J})$ \\
\hline$P_{L, C u}$ & & Machine copper losses (W) & $E_{l o s s, s w D}$ & Diode switching losses $(\mathrm{J})$ \\
\hline$P_{L, F e}$ & & Motor magnetic losses (W) & $\eta_{\text {mot }}$ & Motor efficiency (\%) \\
\hline$P_{\text {cond }, I G B}$ & & IGBT conduction losses (W) & $\eta_{\text {inv }}$ & Inverter efficiency (\%) \\
\hline$T_{s w}$ & & Switching period (s) & $\eta_{d r i v}$ & Drive efficiency (\%) \\
\hline$f_{s w}$ & & Switching frequency $(\mathrm{Hz})$ & & \\
\hline List of Ac & rony & ms & & \\
\hline EKF & Ext & ended Kalman Filter & MTPV & Maximum Torque per Volt \\
\hline ELO & Ext & ended Luemberger Observer & NEDC & New European Driving Cycle \\
\hline EMF & Elec & ctro-Motive Force & PI & Proportional Integral \\
\hline EUDC & Ext & ra Urban Driving Cycle & PLL & Phase Locked Loop \\
\hline EV & Elec & ctric Vehicle & $\mathrm{PM}$ & Permanent Magnet \\
\hline FFT & Fast & t Fourier Transform & $\mathrm{RCP}$ & Rapid Control Prototyping \\
\hline FPGA & Fiel & Id Programmable Gate Array & STA & Super-Twisting Algorithm \\
\hline FW & Fiel & ld Weakening & SynRM & Synchronous Reluctance Machine \\
\hline $\mathrm{HF}$ & Hig & h Frequency & SMC & Sliding Mode Control \\
\hline HFI & Hig & h Frequency Injection & SMO & Sliding Mode Observer \\
\hline IGBT & Insu & ulated Gate Bipolar Transistor & UDC & Urban Driving Cycle \\
\hline IPMSM & Inte & rior Permanent Magnet Synchronous Machine & VCT & Voltage Constraint Tracking \\
\hline LUT & Loo & k-Up Table & VSI & Voltage Source Inverter \\
\hline MRAS & Moc & del Reference Adaptive System & WLTP & Worldwide Harmonized Light Vehicles Test \\
\hline MTPA & Max & ximum Torque per Ampere & & \\
\hline
\end{tabular}


In general purpose drives as well as in the automotive applications, the most widely used rotor position sensors are either the analog resolvers or digital (pulses) encoders. However, their use can cause not only a reduction in reliability, but also additional costs and an increase in the size of the electric drive. Therefore, there is a special interest in their elimination and this is why the so called sensorless control techniques are still widely investigated in both research institutes and industry $[16,17]$.

A large number of back-EMF observer-based sensorless control approaches have been reported in the scientific literature. One well-known example is the Extended Kalman Filter (EKF) for rotor angle estimation that is suitable for non-linear systems and noisy environments [18, 19]. However, the major drawbacks of this method are the complex tuning of the covariance matrices of the EKF equations and the high computational burden required during the state space estimation process [20]. Other alternative sensorless control techniques are the Extended Luenberger Observers (ELO) [21, 22] which, in principle, have the same algorithm of the previously mentioned EKF, but the single difference relies on their tuning, which is analytical and based on the pole placement technique. Despite the covariance matrices do not exist, ELOs still suffer from high computational burden.

A rather different observers family are the Sliding Mode Observers (SMO) [16, 23, 24], whose main advantages are their robustness and low sensitivity to machine parameter variations. However, their limited sampling rate produces chattering problems, requiring additional robust strategies to overcome rotor position estimation errors.

Finally, another approach is based on the Model Reference Adaptive Systems (MRAS) [22], where the estimation is carried out by comparing a reference and an adjustable model. The milestone of such technique is the adaptive mechanism design with the required compromise between fast response and high robustness against noise and disturbances.

Regarding implementation aspects, automotive microcontrollers must comply with the functional safety standards (ISO 26262 ASIL D and IEC 61508 SIL 3). In accordance to this, some well-established automotive microcontrollers are: Freescale MPC5643L (120 MHz), MPC5675K (180 MHz), MPC5744P (200 MHz), and Texas Instruments TMS570 (180 MHz). Considering their limited computational capabilities and industrial demand for additional control and monitoring functionalities, simple sensorless algorithms are desirable at a low computational cost [25]. Hence, Phase Locked Loop (PLL) based estimators $[14,23,26]$ can be considered appropriate for automotive applications.

All these estimation techniques fail at very low speeds or at standstill, due to the lack of back-EMF [27]. Consequently, they must be combined with other strategies. High Frequency Injection (HFI) techniques can be used to obtain the rotor position at very low speeds, including standstill [27-31]. Taking the above into account, this pa- per presents a hybrid sensorless control strategy that uses a PLL for rotor position estimation at medium/high speeds and an HFI technique for low speeds and standstill (figure 1). These estimators have been combined with a robust torque regulation strategy consisting of a Second Order Sliding Mode Control (SMC) algorithm for current regulation, complemented with a Look-up Table (LUT)/Voltage Constraint Tracking (VCT) based optimum current set point generator (figure 1). The proposal is implemented and experimentally validated for a $51 \mathrm{~kW}$ automotive grade PM-assisted SynRM drive. Additionally, the most relevant requirements of the sensorless algorithm, i.e., the injection voltage magnitude, frequency and operation speed threshold, are all determined.

Various drawbacks should be pointed out in relation to the use of HFI techniques [32-34]:

- A high frequency test signal is injected into the EV drive, which produces an additional torque ripple and power losses.

- Relatively high acoustic noise is produced, as the fundamental frequency of the injected signal is within the audible range.

- Additional stress in the mechanical components is introduced, due to the high frequency torque ripple effect.

Thus, the impact of the HFI algorithm should be analyzed, in order to determine its feasibility for real EV applications. A second and a third contribution of this study are, respectively, a power loss characterization model with a study of additional power losses and a study of both the efficiency and the autonomy of an EV relying on HFI. Both contributions provide valuable information on sensorless operation. A detailed simulation model was implemented in a Matlab/Simulink based RT-Lab OP4510 platform, which included the dynamics of a light-duty vehicle, power semiconductor losses (conduction and switching losses at IGBTs and diodes), and (copper and magnetic) losses in the electric machine. In doing so, a detailed estimation of additional HFI losses under the NEDC standardized driving cycle [35, 36] was conducted and their distribution between the drive elements was determined.

\section{Proposed hybrid sensorless control strategy for synchronous machines}

\subsection{Torque control loop}

The torque control loop of the proposed strategy is based on second order Sliding Mode Control (SMC) current regulators and an optimal current set-point generator (figure 1). The second order SMC technique was selected among other control strategies, because of its robustness against parameter variations (which can be significant in automotive synchronous machines), and because it operates at a fixed switching frequency [37]. The $d q$ reference 


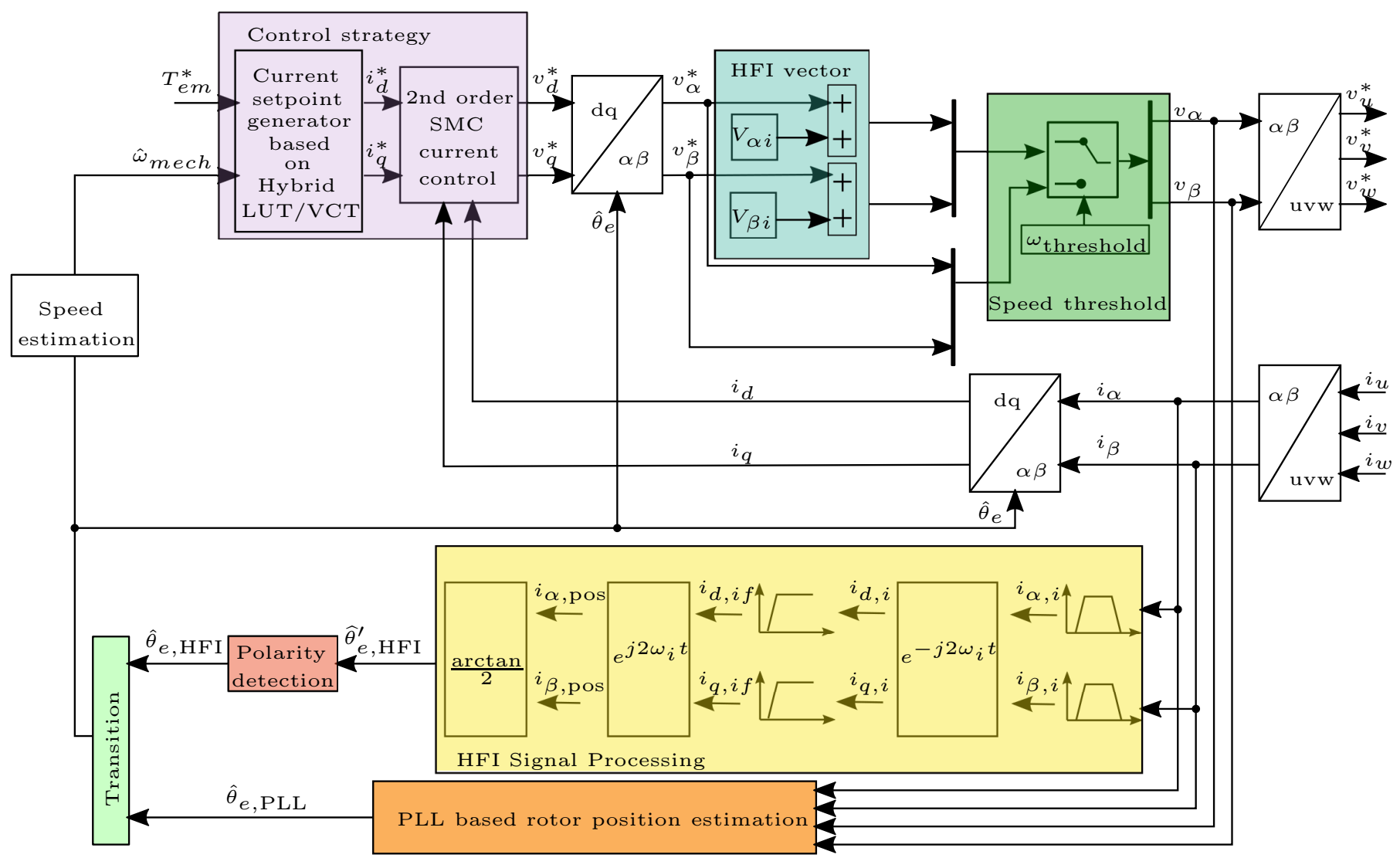

Figure 1: General diagram of the hybrid HFI/PLL sensorless control strategy, including HF voltage vector injection, measured current post-processing, and the transition between both techniques.

voltages for application in the stator (figure 1) were obtained by applying the following control law [15]:

$$
\begin{aligned}
& v_{d}^{*}=v_{d, S T}+v_{d, e q}, \\
& v_{q}^{*}=v_{q, S T}+v_{q, e q} .
\end{aligned}
$$

The terms $v_{d, e q}(3)$ and $v_{q, e q}(4)$ correspond to the equivalent control signals, while $v_{d, S T}$ and $v_{q, S T}$ are computed by applying the Super-Twisting Algorithm (STA) in (5) and (6) [38].

$$
\begin{gathered}
v_{d, e q}=L_{d}\left(c_{d} e_{i_{d}}-\frac{-R_{s} i_{d}+w_{e} \Psi_{q}}{L_{d}}\right), \\
v_{q, e q}=L_{q}\left(c_{q} e_{i_{q}}-\frac{-R_{s} i_{q}-w_{e} \Psi_{d}}{L_{q}}\right), \\
v_{d, S T}=L_{d}\left[\lambda_{d}\left|s_{i_{d}}\right|^{1 / 2} \operatorname{sgn}\left(s_{i_{d}}\right)+\Omega_{d} \int \operatorname{sgn}\left(s_{i_{d}}\right) d t\right], \\
v_{q, S T}=L_{q}\left[\lambda_{q}\left|s_{i_{q}}\right|^{1 / 2} \operatorname{sgn}\left(s_{i_{q}}\right)+\Omega_{q} \int \operatorname{sgn}\left(s_{i_{q}}\right) d t\right],
\end{gathered}
$$

where, $R_{s}$ is the stator resistance; $\omega_{e}$ is the electrical speed; $i_{d}$ and $i_{q}$ are the stator currents in the synchronous reference frame; $L_{d}, L_{q}, \Psi_{d}$ and $\Psi_{q}$ are the stator inductances and flux linkages; $e_{i_{d}}=\left(i_{d}^{*}-i_{d}\right)$ and $e_{i_{q}}=\left(i_{q}^{*}-i_{q}\right)$ are the current regulation errors; and, $c_{d}, c_{q}, \lambda_{d}, \lambda_{q}, \Omega_{d}$ and $\Omega_{q}$ are the positive gains for tuning: $\operatorname{sgn}\left(s_{i_{d}}\right)=s_{i_{d}} /\left|s_{i_{d}}\right|$ and $\operatorname{sgn}\left(s_{i_{q}}\right)=s_{i_{q}} /\left|s_{i_{q}}\right|$ and

$$
\begin{aligned}
& s_{i_{d}}=e_{i_{d}}+c_{d} \int e_{i_{d}} d t, \\
& s_{i_{q}}=e_{i_{q}}+c_{d} \int e_{i_{q}} d t .
\end{aligned}
$$

Determination of the optimum current set points, $i_{d}^{*}$ and $i_{q}^{*}$, (figure 1 ) throughout the whole operational range of the machine, i.e. Maximum Torque Per Ampere (MTPA), Field Weakening (FW), and Maximum Torque per Volt (MTPV) regions $[15,39,40]$ is a complex task for machines with significant saliency. For that reason, $i_{d}^{*}$ and $i_{q}^{*}$ were calculated offline and stored in LUTs. The determination of the set points can be done iteratively from the analytical solutions [39], or by using optimization algorithms such as the Matlab/Simulink fmincon function [41]. Finally, an additional Voltage Constraint Tracking (VCT) feedback was proposed by the authors in [15], in order to improve the robustness of the LUT-based current set point determination during FW. It has since been successfully introduced in the proposed sensorless algorithm. 


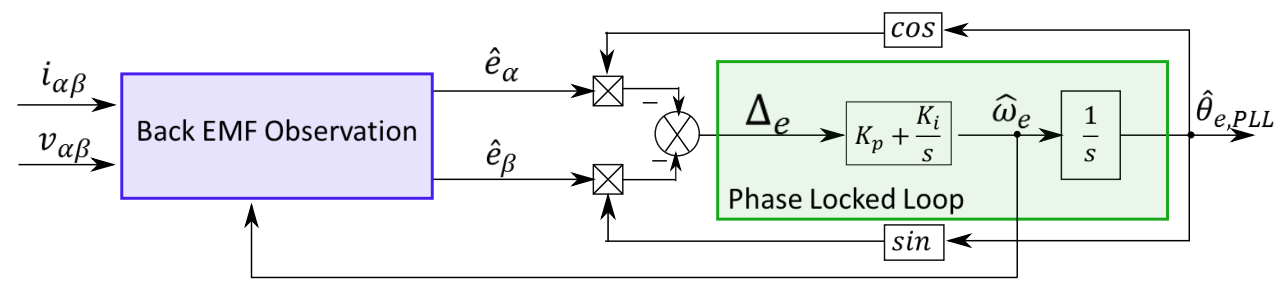

Figure 2: PLL-based rotor position estimation diagram.

As the control loop requires both Park transformation and anti-transformation to function, it becomes clear that the rotor position angle needs to be precisely determined. In this study, a hybrid rotor position estimation approach will be introduced and described in the following section.

\subsection{Medium-to-high speed sensorless strategy}

A PLL-based observer (figure 2) was implemented for rotor position estimation at medium-to-high speeds, due to its simplicity and its low computational burden, which is an important feature for the integration of a sensorless control algorithm in automotive grade microcontrollers with limited computational capabilities.

Using the PLL approach, the estimated $\alpha \beta$ components of the back-EMF (figure 2, back-EMF observation block) were obtained from the following conventional stator voltage equations:

$$
\widehat{\mathbf{e}}_{\alpha \beta}=\mathbf{v}_{\alpha \beta}-R_{s} \mathbf{i}_{\alpha \beta}-L_{s} \frac{d \mathbf{i}_{\alpha \beta}}{d t},
$$

where, $\mathbf{i}_{\alpha \beta}$ and $\mathbf{v}_{\alpha \beta}$ are the measured phase currents and voltages expressed in the $\alpha \beta$ coordinates, and $L_{s}$ is the stator nominal inductance value. It is important to point out that automotive synchronous machines are generally designed to obtain a significant saliency $\left(L_{d}<L_{q}\right)$, in such a way as to maximize the reluctant torque production and the power density [15]. As a consequence, the stator inductance in the $\alpha \beta$ plane depends on the rotor position, which implies a non-Linear Time-Invariant (LTI) system with a complex solution. A simplification of the problem is required to operate the voltage equation [42]. Hence, $L s=\left(L_{d}+L_{q}\right) / 2$, was considered in this study.

The following expression was obtained, by operating the resultant estimated back-EMF components according to the structure shown in figure 2 [43]:

$$
-\widehat{\mathbf{e}}_{\alpha} \cos \left(\widehat{\theta}_{e, P L L}\right)-\widehat{\mathbf{e}}_{\beta} \sin \left(\widehat{\theta}_{e, P L L}\right)=\widehat{w}_{e} \Psi_{P M} \Delta_{e},
$$

where, $\widehat{w}_{e}$ is the estimated electrical speed; $\widehat{\theta}_{e, P L L}$ is the estimated electrical position; and $\Delta_{e}=\widehat{\theta}_{e, P L L}-\theta_{e}$ is the angle deviation. The Proportional Integral (PI) controller minimizes this error; consequently, the estimated value $\widehat{\theta}_{e, P L L}$ tracks the real electrical angle.

The PLL, EKF, and SMO strategies were implemented in Matlab/Simulink and were run in real time in a single computational node of an RT-Lab OP4510 digital simulator (Intel Xeon E3 4 core CPU, 3.2 GHz), in order to demonstrate the low computational burden required by the PLL algorithm. Using the tools provided by OPAL-RT for analysis and monitoring, it was verified that the PLL algorithm could be executed at speeds that were $35.6 \%$ and $13.9 \%$ faster than the EKF and SMO, respectively.

\subsection{Low speed and standstill sensorless strategy}

HFI techniques (figure 1) are considered appropriate, to obtain information on rotor position at very low speeds and at standstill, due to their independence from the backEMF $[27,28]$. A rotating $\mathrm{HF}$ voltage vector was added to the stator voltage references, in order to establish the rotor position (figure 1, HFI vector block):

$$
\mathbf{v}_{i}=\left[\begin{array}{c}
v_{\alpha i} \\
v_{\beta i}
\end{array}\right]=V_{i}\left[\begin{array}{c}
-\sin \left(w_{i} t\right) \\
\cos \left(w_{i} t\right)
\end{array}\right]
$$

where, $V_{i}$ is the amplitude of the HF signal that is introduced; and, $w_{i}$ is the angular speed of rotation. The currents that are measured, due to the saliency of the machine, contain the rotor position at $w_{i} t$ [27], which requires a current signal post-processing procedure (figure 1, signal processing block), details of which may be found in [27, 28, 43].

Three important requirements must be considered for proper adjustment of the HFI-based sensorless controller:

1 The magnitude of the rotating injected frequency has to be determined. This frequency is usually set at around 10 times higher than the fundamental frequency of the electrical machine and 10 times lower than the power converter switching frequency [33]. For example, a rotation frequency of $f_{i}=1 \mathrm{kHz}$ is typically used for power converters with a switching frequency of around $10 \mathrm{kHz}[27,28]$.

2 The injected voltage amplitude $V_{i}$ is selected in an empirical process, taking into account that an excessively low voltage amplitude will not produce enough current for angle estimation and that torque fluctuations will be greater when the value of $V_{i}$ is increased [33].

3 A speed threshold $\omega_{t h}$ that determines the transition point between the HFI and the observer needs 


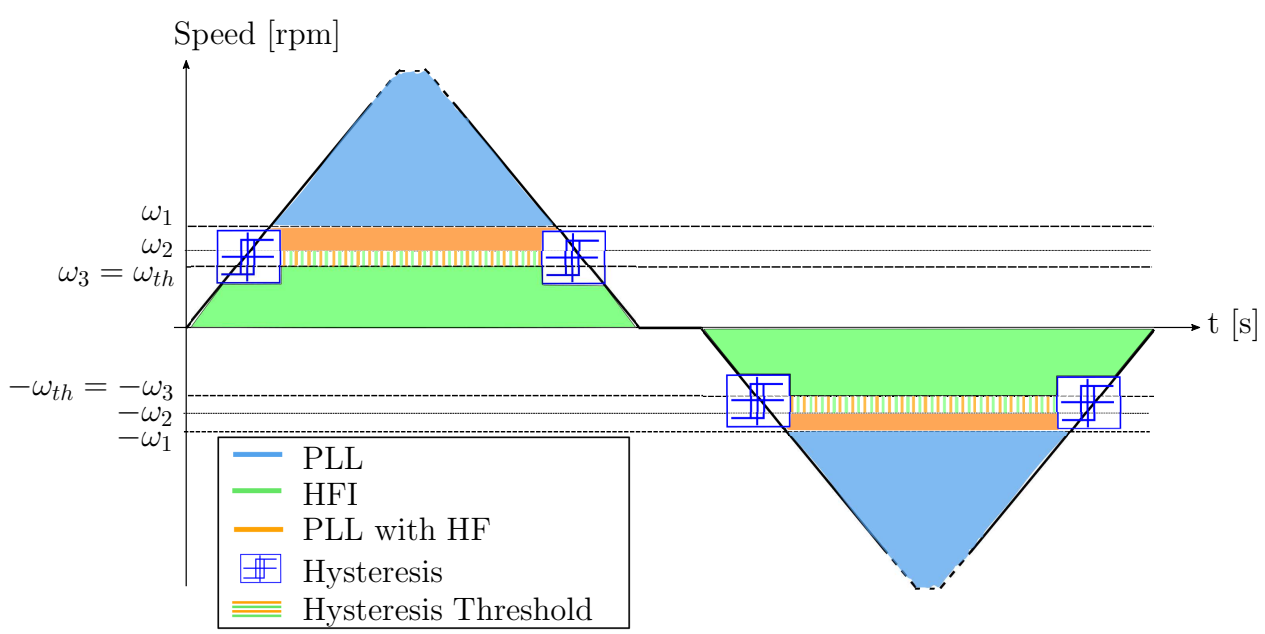

Figure 3: Conceptual operation diagram of the proposed hybrid sensorless control strategy, including transition points and operation regions.

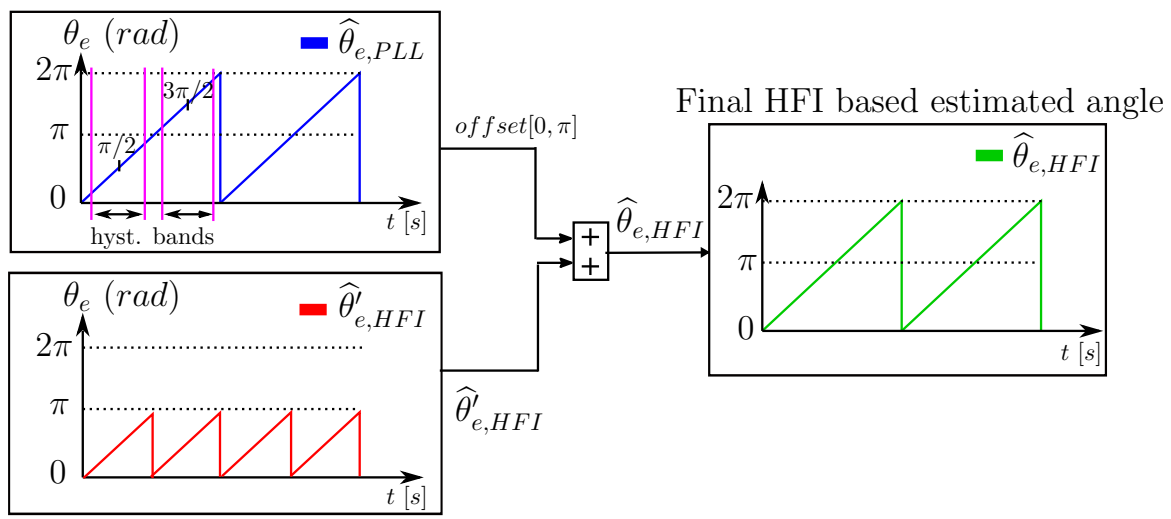

Figure 4: HFI polarity determination algorithm during transitions from PLL to HFI algorithms.

to be empirically adjusted (figure 1 , speed threshold and transition blocks) [43]. This threshold must be set at a sufficiently low value to ensure that there is enough back-EMF for correct estimation of the position by the observer. In this way, the injection of $\mathrm{HF}$ perturbations will be minimized.

The HFI technique can not distinguish the north and the south poles of the magnet. It therefore generates an angle between 0 and $\pi$, leading to possible angle estimation errors of $\pi$ rad. As this error value might be unacceptable (if it reversed the polarity of the torque), the integration of the HFI technique in the control algorithm requires a procedure that will permit a smooth transition between the HFI and the PLL algorithms. In this context, the authors proposed a procedure in [43], the operating principle of which is illustrated in figure 3 .

The PLL estimates the angular position above the speed threshold $|\omega 1|$, while the HFI is deactivated. When the machine reduces its speed and the operating speed is between $|\omega 1|$ and $|\omega 2|$, the angle obtained from the PLL is still used by the controller, while the HFI technique is activated to start converging. An hysteresis band between $|\omega 1|$ and $|\omega 3|=\left|\omega_{t h}\right|$ is included to change from the angle provided by the PLL to the one provided by the HFI, avoiding multiple changes around these speeds. The opposite procedure is performed when accelerating.

Taking into account that HFI is restricted to low-speed operation and standstill, the angle polarity must be checked each time the HFI algorithm is reactivated to restore $\widehat{\theta}_{e, H F I}$ properly $[27,43]$. The position polarity determination strategy (figure 4) is based on the information obtained from the PLL-based angle estimator. The transition algorithm determines the required position polarity compensation from $\widehat{\theta}_{e, P L L}$ as follows:

$$
\widehat{\theta}_{e, H F I}= \begin{cases}\widehat{\theta}_{e, H F I}^{\prime}+0 & \text { if } \widehat{\theta}_{e, P L L}=\frac{\pi}{2} \pm H y s t, \\ \widehat{\theta}_{e, H F I}^{\prime}+\pi & \text { if } \widehat{\theta}_{e, P L L}=\frac{3 \pi}{2} \pm \text { Hyst }\end{cases}
$$

where, Hyst is an hysteresis band that is included to avoid errors in polarity determination, due to possible angle offsets between both estimators. In this way, a reliable change 


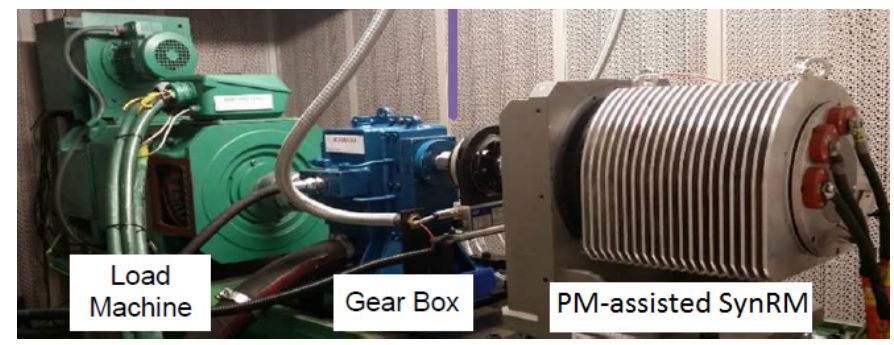

Figure 5: Automotive grade testbench.

Table 1: Most significant parameters of the PM-assisted SynRM machine.

\begin{tabular}{|c|c|c|c|}
\hline Item & Symbol & Value & Units \\
\hline Maximum power & $P_{N}$ & 51 & $\mathrm{~kW}$ \\
\hline Maximum speed & $w_{\max }$ & 12000 & $\mathrm{rpm}$ \\
\hline Machine Pole Pairs & $P$ & 3 & - \\
\hline Stator Resistance & $R_{s}$ & 0.012 & $\Omega$ \\
\hline d-axis nominal inductance & $L_{d}$ & $0.7 \mathrm{e}^{-} 3$ & $\mathrm{H}$ \\
\hline q-axis nominal inductance & $L_{q}$ & $1.7 \mathrm{e}^{-} 3$ & $\mathrm{H}$ \\
\hline Permanent Magnet Flux linkage & $\Psi_{P M}$ & 0.38 & $\mathrm{~Wb}$ \\
\hline Magnetic Resistance & $R_{F e}$ & 20 & $\Omega$ \\
\hline
\end{tabular}

is assured.

\section{Experimental validation}

\subsection{Experimental platform description}

The proposed hybrid sensorless strategy was validated in an automotive grade test bench (figure 5), composed of the following main components:

- An induction load machine of $8000 \mathrm{rpm}$ and $157 \mathrm{~kW}$, which emulates the behavior (speed and torque characteristics) of an electric vehicle.

- A 1:1.8 Gearbox between the load and test machine.

- A dSPACE Rapid Control Prototyping (RCP) digital device, equipped with a DS1006 DSP board and an AC Motor Control Solutions board.

- An industrial power converter (Semikron IGD-1-424P1N4-DL-FA) with a nominal power of $140 \mathrm{~kW}$ and a maximum switching frequency of $25 \mathrm{kHz}$.

- A torquimeter (HBM T40B).

The hybrid sensorless strategy was validated in a $51 \mathrm{~kW}$ PM-assisted SynRM, the most important nominal parameters of which are shown in table 1.

\subsection{Determination of HFI requirements and experimental validation of the proposed sensorless control algorithm}

At a first stage, the most significant HFI parameters were set using a trial and error procedure, where the minimum $V_{i}$ and $\omega_{t h}$ values that ensure a robust sensorless operation were determined. In this particular application, $V_{i}$ was set at $60 V(18.75 \%$ of the available DC bus) at a rotating frequency of $1 \mathrm{kHz}$ and with a speed threshold $\left|\omega_{t h}\right|=|\omega 3|$ of $800 \mathrm{rpm}(6.67 \%$ of the SynRM speed range). Additionally, the values $|\omega 1|=1000 \mathrm{rpm}$, $|\omega 2|=975 \mathrm{rpm}$ and Hyst $=1.5 \mathrm{rad}$ were considered for the parametrization of the transition algorithm.

Figure 6 shows the results of the proposed hybrid sensorless strategy operating in both motor and generator mode, including positive speed, speed reversal and standstill operation. The estimated torque from measured currents vs the measured torque (figure 6(a)), the measured currents (figure 6(b)), the estimated speed (figure 6(c)), and the estimated rotor position (figure 6(d)) all showed the satisfactory performance of the sensorless control algorithm. As can be seen from the figures, relatively high electromagnetic torque and current ripple values were introduced when the HFI technique was activated. Note that the torquimeter cannot measure the high frequency torque component. Figure 7 shows a detail of the currents measured in the $\alpha \beta$ plane (figure 7 (a)), including a Fast Fourier Transform (FFT) of $\alpha$, from which the HF component at the rotating frequency $f_{i}=1 \mathrm{kHz}$ is obtained (figure $7(\mathrm{~b})$ ). Finally, figure 8 shows sensorless torque control operation above the base speed, confirming satisfactory torque regulation during field weakening.

Thus, the HFI method ensures correct rotor position and speed estimation both at low speeds and at standstill, at the cost of increasing the drive losses, as shown in figures $6(\mathrm{a})$ and $6(\mathrm{~b})$. Its impact on drive performance can be minimized by means of a correct adjustment of $V_{i}$ and $w_{t h}$, which are highly influenced by the electrical parameters of the machine. If the electric machine is designed with a higher permanent magnet flux $\left(\Psi_{P M}\right)$, the observer operation range could be extended, or in other words, the speed threshold, $w_{t h}$, could be shortened: in addition, the higher the saliency of the machine, the lower the required value of $V_{i}$.

In the following sections, the impact of the HFI sensorless technique on the power losses and the efficiency of a light-duty EV drive will be analyzed under the standard NEDC driving cycle. As a first step, an accurate motor and inverter loss model, including driving cycle simulation capability, was developed to quantify the aforementioned parameters. Focusing on the experimentally determined HFI parameters, this study was extended to various combinations of $V_{i}$ and $w_{t h}$, in order to arrive at conclusions on the desired features of a sensorless drive design.

\section{Power loss characterization in EV drive systems}

\subsection{Synchronous machine electrical model}

A synchronous machine can be mathematically represented using the synchronous $d q$ reference frame, where the $d$-axis is in the direction of permanent magnet flux. Neglecting the iron losses, the equations for stator voltages in the $d q$ reference frame are [44]: 


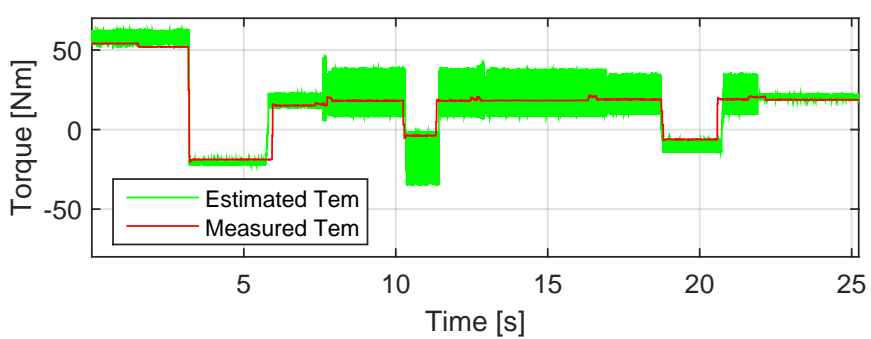

(a) Estimated torque from measured currents and measured torque.

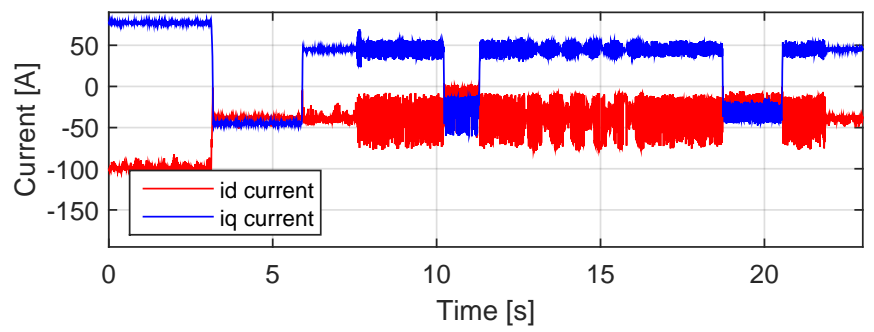

(b) Measured currents in the dq axis.

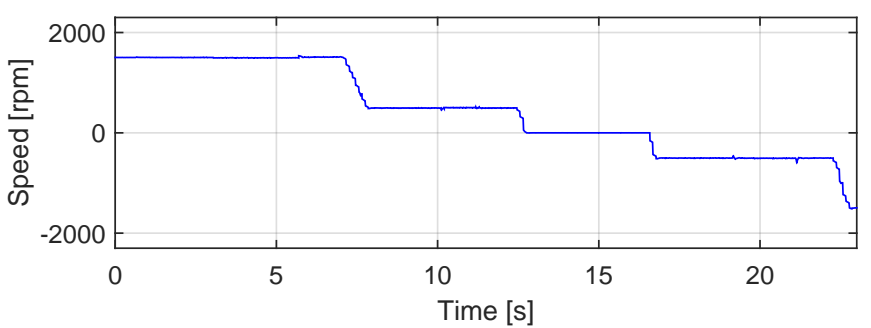

(c) Estimated mechanical speed.

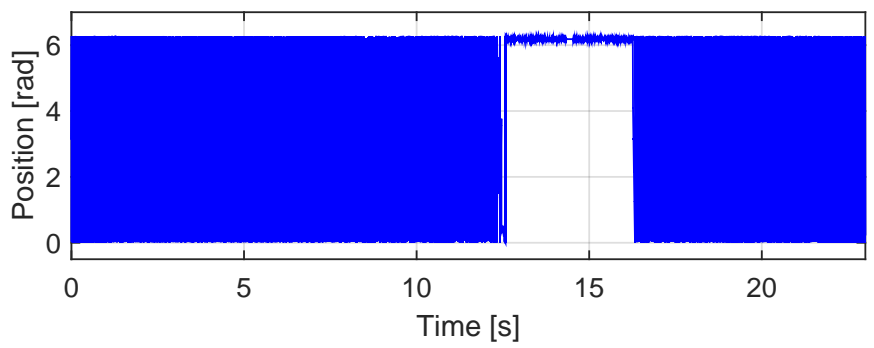

(d) Estimated rotor position.

Figure 6: Hybrid sensorless torque control operation in four quadrants showing smooth transitions between both rotor position estimators.

$$
\begin{aligned}
& v_{d}=R_{s} i_{d}+\frac{d \Psi_{d}}{d t}-\omega_{e} \Psi_{q}, \\
& v_{q}=R_{s} i_{q}+\frac{d \Psi_{q}}{d t}+\omega_{e} \Psi_{d},
\end{aligned}
$$

where, $v_{d}$ and $v_{q}$ are the phase voltages; $\omega_{e}$ is the electrical angular speed of the rotor; and $\omega_{e}=P \omega_{\text {mech }}$ and $P$ are the machine pole-pairs.

The stator flux components, $\Psi_{d}$ and $\Psi_{q}$, can be represented as:

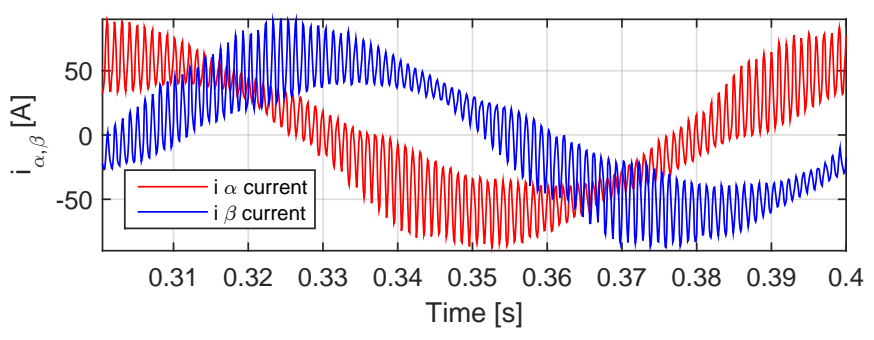

(a) $i_{\alpha \beta}$ measured currents including HF.

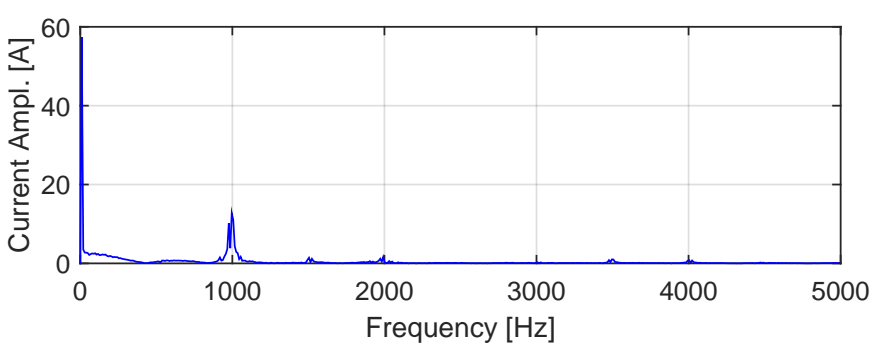

(b) Spectrum of $i_{\alpha}$ measured current including HF.

Figure 7: Measured currents in the $\alpha \beta$ axis when the HFI technique is enabled.

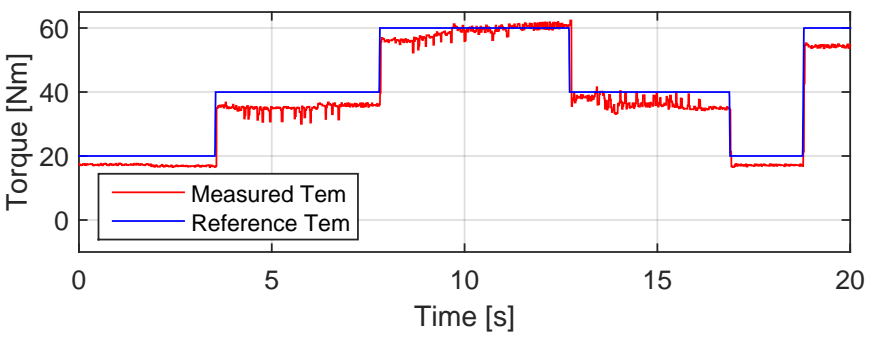

(a) Torque control (reference torque vs measured torque).

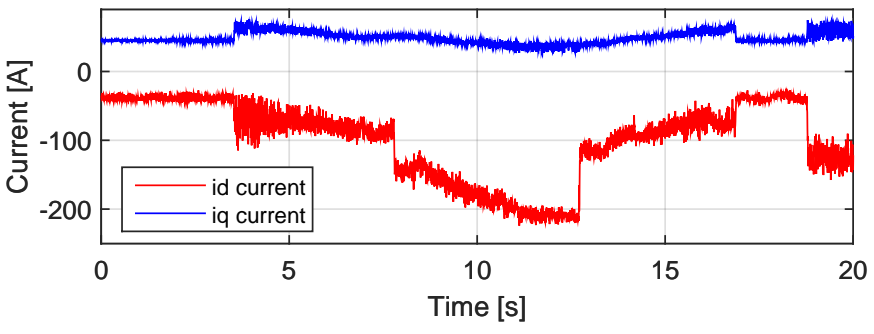

(b) Measured currents in the dq axis.

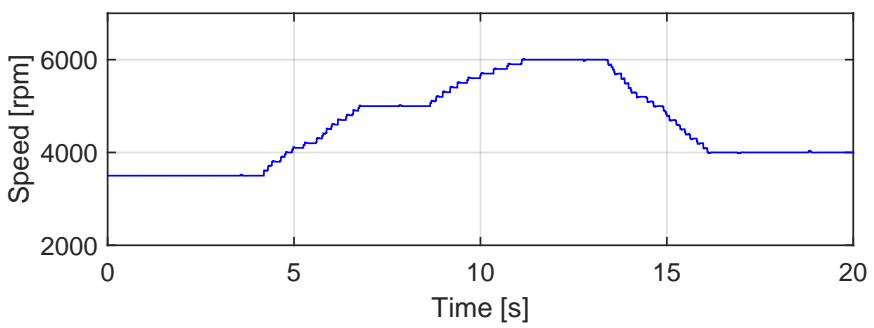

(c) Estimated mechanical speed.

Figure 8: Hybrid sensorless torque control experimental results at medium/high speeds in FW operation. 


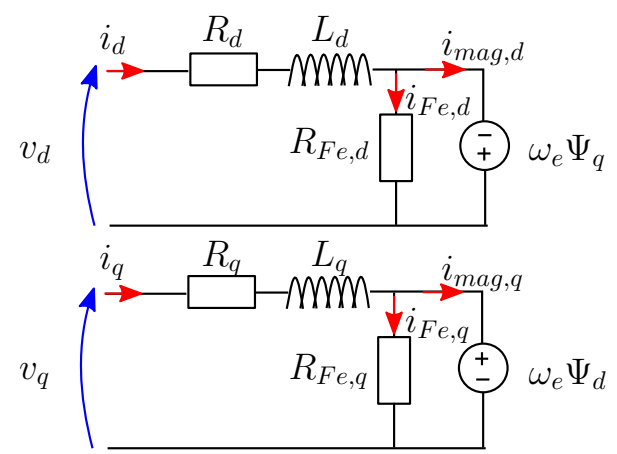

Figure 9: Equivalent machine stator voltage circuits.

$$
\begin{gathered}
\Psi_{d}=L_{d} i_{d}+\Psi_{P M}, \\
\Psi_{q}=L_{q} i_{q},
\end{gathered}
$$

where $\Psi_{P M}$ is the flux linkage produced by the permanent magnets. The electromagnetic torque is given by the following expression:

$$
T_{e m}=\frac{3}{2} P\left\{\Psi_{d} i_{q}-\Psi_{q} i_{d}\right\} .
$$

\subsection{Synchronous machine model including power losses}

Motor electrical power losses consist of iron and copper losses $[45,46]$. Fictive resistors, $R_{F e, d}$, and, $R_{F e, q}$, were added to the equivalent stator voltage circuits, in order to represent the impact of the iron losses produced by the fundamental stator electrical frequency (figure 9):

$$
\begin{gathered}
i_{F e, d}=-\frac{\omega_{e} \Psi_{q}}{R_{F e, d}}, \\
i_{F e, q}=\frac{\omega_{e} \Psi_{d}}{R_{F e, q}},
\end{gathered}
$$

where,

$$
\begin{aligned}
& i_{m a g, d}=i_{d}-i_{F e, d}, \\
& i_{m a g, q}=i_{q}-i_{F e, q},
\end{aligned}
$$

In which, $i_{F e, d}$ and $i_{F e, q}$ are the iron loss currents; and, $i_{m a g, d}$ and $i_{m a g, q}$ are the magnetizing currents responsible for torque production. Taking into account the iron losses in the electromagnetic torque equation, phase currents in (17) must be replaced by (20) and (21), as follows:

$$
\begin{gathered}
T_{e m}=\frac{3}{2} P\left(\Psi_{d} i_{m a g, q}-\Psi_{q} i_{m a g, d}\right), \\
T_{e m}=\frac{3}{2} P\left[\Psi_{d}\left(i_{q}-\frac{\omega_{e} \Psi_{d}}{R_{F e}}\right)-\Psi_{q}\left(i_{d}+\frac{\omega_{e} \Psi_{q}}{R_{F e}}\right)\right] .
\end{gathered}
$$

In contrast, the total power losses of a motor consisting of its iron and copper losses can be represented as [47, 48]:
$P_{L}=P_{L, C u}+P_{L, F e}=\frac{3}{2}\left[R_{s}\left(i_{d}^{2}+i_{q}^{2}\right)+\frac{\omega_{e}^{2}}{R_{F e}}\left(\Psi_{d}^{2}+\Psi_{q}^{2}\right)\right]$.

When HFI is introduced, the additional current ripple produced by the injection and the following iron loss term must also be included (24) to represent the additional losses:

$$
P_{F e}^{H F I}=\frac{3}{2} \frac{\omega_{i}^{2}}{R_{F e}^{H F I}}\left(\Psi_{d, H F I}^{2}+\Psi_{q, H F I}^{2}\right),
$$

where, $R_{F e}^{H F I}$ is the magnetic resistance at $\omega_{i}$; and, $\Psi_{d, H F I}$ and $\Psi_{q, H F I}$ are the magnetic fluxes produced by the $\mathrm{HF}$ component on the $d$ - and $q$-axes, respectively.

\subsection{Voltage Source Inverter power losses}

Calculation of the conduction and the switching losses of each IGBT and diode [49] are required, in order to determine the power losses of the Voltage Source Inverter (VSI) responsible for synthesizing the electric machine phase voltages. Considering a given gate resistance, $R_{g}$, and a DC link voltage, $V_{D C}$, the average conduction losses of a single IGBT over a modulation period can be expressed as:

$$
P_{\text {cond }, I G B T}=\frac{1}{T_{s w}} \int_{0}^{T_{s w}} V_{c e}\left(i_{c}, T_{v j, I G B T}\right) i_{c}(t) d t,
$$

where, $V_{c e}\left(i_{c}, T_{v j, I G B T}\right)$ is the collector-emitter voltage drop; $i_{c}(t)$ is the instantaneous current circulating through the semiconductor; $T_{s w}$ is the modulation period; and, $T_{v j, I G B T}$ is the virtual junction temperature of the IGBT. The switching losses of the IGBT during a modulation period can be expressed as:

$$
P_{s w, I G B T}=\frac{1}{T_{s w}}\left[E_{O N}\left(i_{c}\right)+E_{O F F}\left(i_{c}\right)\right],
$$

where, $E_{O N}\left(i_{c}\right)$ and $E_{O F F}\left(i_{c}\right)$ are the instantaneous energy losses produced in the ON and OFF switching instants (figure 10), respectively. Similarly, the conduction and switching losses of the anti-parallel diode during a modulation period can be expressed as:

$$
\begin{gathered}
P_{\text {cond }, D}=\frac{1}{T_{s w}} \int_{0}^{T_{s w}} V_{F}\left(i_{F}, T_{v j, D}\right) i_{F}(t) d t, \\
P_{s w, D}=\frac{1}{T_{s w}} E_{R R}\left(i_{F}\right),
\end{gathered}
$$

where, $V_{F}\left(i_{F}, T_{v j, D}\right)$ is the diode forward voltage; $i_{F}(t)$ is the instantaneous current circulating through the diode; $T_{v j, D}$ is the virtual junction temperature of the diode; and, $E_{R R}\left(i_{F}\right)$ is the reverse recovery energy loss (figure 10).

Finally, the total instantaneous inverter losses can be expressed as: 


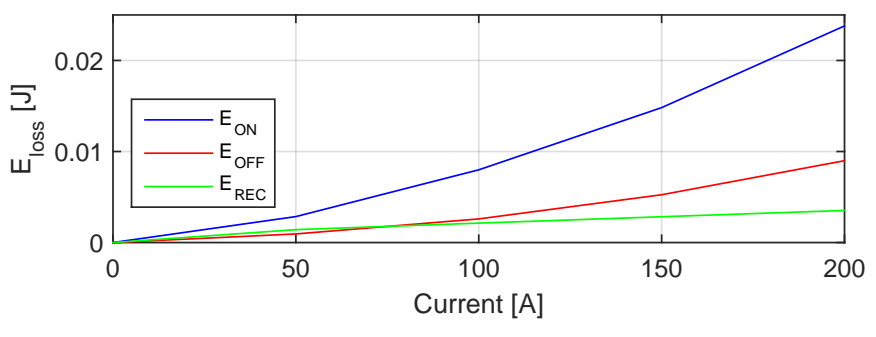

Figure 10: $E_{O N}, E_{O F F}$ and $E_{R R}$ energy losses vs current for the discrete IR AUIRGPS4067D1 IGBT (at $175^{\circ} C$ and $V_{C E}=400 \mathrm{~V}$ ).

Table 2: Most relevant parameters of the simulated power electronics system including IR AUIRGPS4067D1 devices.

\begin{tabular}{|c|c|c|c|}
\hline \multicolumn{5}{|c|}{ IGBT and diode parameters } \\
\hline Parameter & Symbol & Value & Units \\
\hline Number of parallel devices & - & 3 & - \\
\hline Maximum current per switch & $I_{c, m a x}$ & 160 & $\mathrm{~A}$ \\
\hline Nominal current per switch & $I_{c, n o m}$ & 10 & $\mathrm{~A}$ \\
\hline Maximum blocking voltage & $V_{c e s}$ & 600 & $\mathrm{~V}$ \\
\hline Typical collector-emitter voltage & $V_{c e, O N}$ & 1.7 & $\mathrm{~V}$ \\
\hline Typical turn-on switching loss & $E_{O N}$ & 8.2 & $\mathrm{~mJ}$ \\
\hline Typical turn-off switching loss & $E_{O F F}$ & 2.9 & $\mathrm{~mJ}$ \\
\hline Typical diode reverse recovery & $E_{R E C}$ & 2.4 & $\mathrm{~mJ}$ \\
\hline Junction temperature & $T_{v j}$ & 85 & ${ }^{\circ} \mathrm{C}$ \\
\hline Power converter parameters & \\
\hline DC link capacitance & $C_{D C}$ & 3 & $\mathrm{mF}$ \\
\hline Switching frequency & $f_{s w}$ & 10 & $\mathrm{kHz}$ \\
\hline Battery voltage & $V_{b a t t}$ & 320 & $\mathrm{~V}$ \\
\hline Gate resistance (ON and OFF) & $R_{G}$ & 5 & $\Omega$ \\
\hline
\end{tabular}

$$
\begin{aligned}
P_{\text {loss }, \text { inv }} & =\sum_{i=0}^{N}\left(P_{\text {cond }, I G B T_{i}}+P_{s w, I G B T_{i}}\right)+ \\
& +\sum_{j=0}^{M}\left(P_{c o n d, D_{j}}+P_{s w, D_{j}}\right)
\end{aligned}
$$

where, $N$ and $M$ are the number of IGBTs and diodes that constitute the VSI, respectively.

Determination of the losses is done with the following ratios: $V_{c e}\left(i_{c}, T_{v j, I G B T}\right), E_{O N}\left(i_{c}\right), E_{O F F}\left(i_{c}\right), V_{F}\left(i_{F}, T_{v j, D}\right)$, and $E_{R R}\left(i_{F}\right)$. They can be extracted from the data provided by the manufacturer, while the virtual junction temperatures $T_{v j, I G B T}$ and $T_{v j, D}$ can be calculated from equivalent Cauer or Foster thermal models [50], which consider the thermal flow path from the semiconductor junction to the heatsink. However, for the sake of simplicity, a constant junction temperature was considered in this paper.

In this particular analysis, a detailed loss model was implemented of a two-level/three-phase Voltage Source Inverter (VSI) specifically dimensioned for the $51 \mathrm{~kW}$ PMassisted SynRM. Three automotive grade discrete IR AUIRGPS4067D1 devices were parallelized, in order to create each switch of the inverter. Table 2 shows the most significant parameters of the power electronics model.

\section{Standardized New European Driving Cycle and vehicle model}

Standardized driving cycles $[35,36,51,52]$ are useful for the analysis of vehicle performance in terms of consumption, pollution, and efficiency. The NEDC is widely used in Europe for evaluating light-duty electric vehicles ensuring realistic results [53]. It consists of a speed-versustime driving profile (figure 11), divided into 4 repeated ECE-15 Urban Driving Cycles (UDC) and an Extra-Urban Driving Cycle (EUDC). Thus, this driving cycle becomes a suitable EV drive operation pattern to analyze the influence of the HFI.

A backward looking vehicle simulation model is used to estimate the required electromagnetic torque, in order to fulfill the NEDC driving cycle. Under this assumption, a simplified vehicle model determines the estimated torque for a given speed profile, from the vehicle back to the engine. In figure 11, the diagram of this vehicle model is presented, which is divided into two main tasks:

- Vehicle model: Obtains the required torque and speed in the wheel, for the specific vehicle class.

- Transmission model: Adapts the previously calculated torque and speed according to the efficiency and gear ratio of the final vehicle transmission. The transmission torque is the one that the electric machine will apply, in order to fulfill the NEDC driving cycle.

The required torque and speed of the wheels can be expressed as:

$$
\begin{gathered}
\omega_{\text {wheel }}=\frac{\omega_{\text {dc }}}{r_{\text {wheel }}}, \\
T_{\text {wheel }}=r_{\text {wheel }}\left(F_{\text {Roll }}+F_{\text {Aero }}+F_{\text {Inertia }}\right),
\end{gathered}
$$

where, $r_{w h e e l}$ is the wheel radius; $\omega_{d c}$ is the speed defined in the NEDC driving cycle; and, $F_{\text {Roll }}, F_{\text {Aero }}$, and $F_{\text {Inertia }}$ are the rolling resistance, aerodynamic resistance, and inertia forces, respectively. These last three can be defined as:

$$
\begin{gathered}
F_{\text {Roll }}=\mu a_{g} M_{\text {car }}, \\
F_{\text {Aero }}=\frac{\rho \omega_{d c}^{2} C_{d} A_{f}}{2}, \\
F_{\text {Inertia }}=\left\{M_{\text {car }}\left(1+M_{\text {rot }}\right)\right\} a_{\text {car }},
\end{gathered}
$$

where, $M_{c a r}$ is the total vehicle mass; $a_{g}$ is the gravity acceleration; $\mu$ is the rolling friction coefficient; $\rho$ is the air density; $C_{d}$ is the drag coefficient; $A_{f}$ is the vehicle cross section; $M_{\text {rot }}$ is the equivalent mass of the rotating parts of the car (expressed in \%); and, $a_{c a r}$ is the car acceleration defined as $d v / d t$. The grade force was considered in this simplified vehicle model. Finally, the required transmission torque is directly calculated from (31) and (32) considering the corresponding gear ratio as follows:

$$
T_{\text {trans }}=\frac{T_{\text {Idling }}+T_{\text {wheel }}}{\mu_{G R} G R},
$$



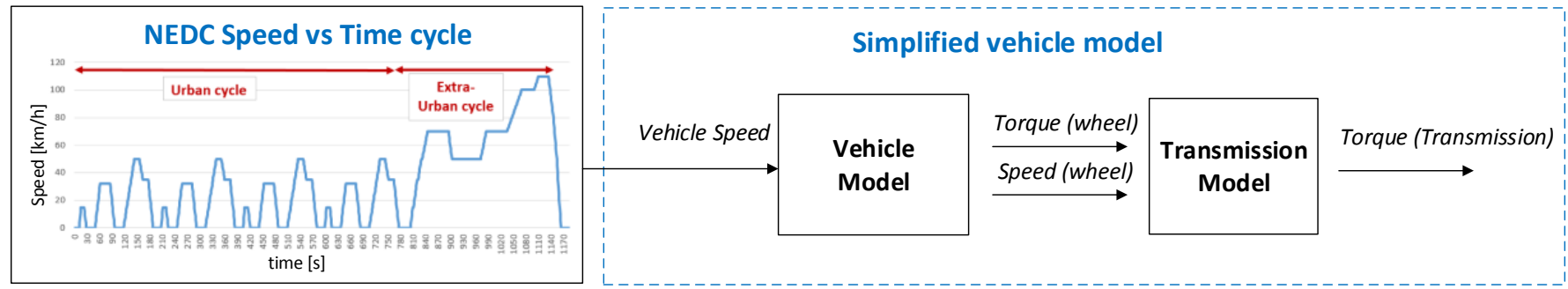

Figure 11: Vehicle model for NEDC torque driving cycle profile generation.

Table 3: Vehicle parameters used for PM-assisted SynRM torque estimation according to the NEDC.

\begin{tabular}{|c|c|c|c|}
\hline \multicolumn{5}{|c|}{ Vehicle Model parameters } \\
\hline Parameter & Symbol & Value & Units \\
\hline Vehicle total mass & $M_{\text {car }}$ & 1030 & $\mathrm{~kg}$ \\
\hline Rotating mass & $M_{\text {rot }}$ & 5 & $\%$ \\
\hline Vehicle cross section & $A_{f}$ & 2.42 & $\mathrm{~m}^{2}$ \\
\hline Wheel radius & $r_{w h e e l}$ & 0.29 & $\mathrm{~m}$ \\
\hline Gravity acceleration & $a_{g}$ & 9.81 & $\mathrm{~m} / \mathrm{s}^{2}$ \\
\hline Rolling friction coefficient & $\mu$ & 0.008 & - \\
\hline Air density & $\rho$ & 1.225 & $\mathrm{~kg} / \mathrm{m}^{3}$ \\
\hline Drag coefficient & $C_{d}$ & 0.367 & - \\
\hline \hline \multicolumn{4}{|c|}{ Transmission Model parameters } \\
\hline Parameter & Symbol & Value & Units \\
\hline Gear ratio & $G R$ & 6.2 & - \\
\hline Efficiency & $\eta_{G R}$ & 97 & $\%$ \\
\hline Idling losses & $P_{\text {Idling }}$ & 300 & $\mathrm{~W}$ \\
\hline \multicolumn{4}{|c|}{ Battery Model parameters } \\
\hline Parameter & Symbol & Value & Units \\
\hline Battery energy & $E_{\text {batt }}$ & 57.6 & MJ \\
\hline
\end{tabular}

where, $G R$ and $\mu_{G R}$ are the gear ratio and its efficiency, respectively. $T_{\text {Idling }}$ corresponds to the idling torque, which is defined as:

$$
T_{\text {Idling }}=\frac{P_{\text {Idling }}}{\omega_{\text {wheel }}},
$$

where, $P_{\text {Idling }}$ represents the idling losses.

Regarding the model vehicle parametrization, a baseline A Segment Full Electric vehicle was defined, where the most significant parameters are shown in table 3 . The brake blending law in this application is defined as $100 \%$ electric braking.

The vehicle model was run offline to obtain a torque vs speed curve that was then stored in Look-up Tables (LUTs) for PM-assisted SynRM drive loss model simulations.

In this particular analysis, simulations were focused only on UDCs. As injection is only activated at low speeds or standstill, the HFI impact in EUDCs is negligible.

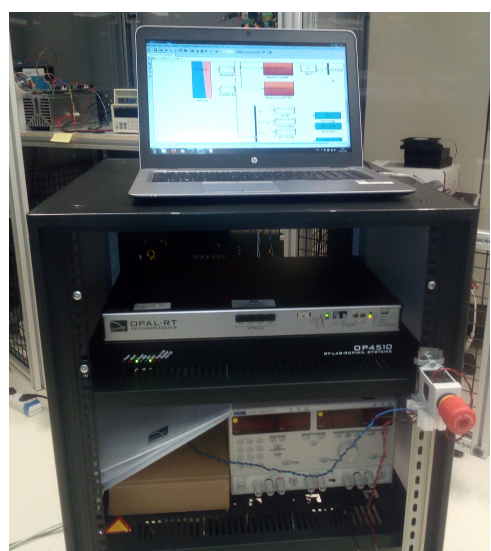

Figure 12: OP4510 real-time digital simulation platform used for the efficiency and power loss simulations of the electric drive under the NEDC driving cycle.

\section{Estimation of HFI impact on power losses, effi- ciency and vehicle autonomy}

\subsection{High performance simulation platform description}

Simulation is widely used for the design and evaluation of modern power systems [54]. However, power electronics simulation can be a time-consuming task, due to differences between the time constants of the various (electrical, mechanical, and thermal) domains involved in a power system, such as in the case of an EV drive. The UDC used in this paper for HFI impact analysis requires simulation of $195 \mathrm{~s}$ of the behavior of the EV drive while, due to the IGBTs high switching frequencies, simulation steps in the order of $1 \mu$ s are required to achieve accurate power electronics simulation results without jitter [55].

Real-time digital simulators with parallel computing capability can be used, in order to accelerate the simulation process and to make it feasible to simulate a detailed loss model under the driving cycle. Figure 12 shows the RT-Lab OP4510 digital real-time simulator, consisting of four parallel computation nodes.

The model was divided into two subsystems (each subsystem was executed in parallel in one computation node), in order to optimize the simulations: 
- Master subsystem: includes the control algorithms and the previously detailed HFI strategy, data logging, and energy and efficiency calculation blocks.

- Slave subsystem: includes the electric machine, the inverter loss models, and the instantaneous power calculations for both the electric machine and the inverter.

With this configuration, on average, it is possible to simulate the whole NEDC cycle with a simulation step of $1 \mu \mathrm{s}$ in 63 minutes, approximately, leading to the following simulation factor:

$$
\Gamma_{\text {sim }}=\frac{t_{\text {sim }}}{t_{\text {behaviour }}}=19.5,
$$

where, $\Gamma_{\text {sim }}=1$ corresponds to a real-time simulation; and, $\Gamma_{\text {sim }}>1$ corresponds to a slower than real-time simulation.

\subsection{UDC simulation results}

The main objective of this simulation study is to quantify the additional power losses introduced by HFI-based sensorless strategies. This approach allows us to determine whether it is possible to use the proposed algorithm (or other similar approaches) continuously in the automotive context. In this context, the sensorless operation was considered ideal (perfect angle tracking), and only the perturbation injection below the speed threshold $w_{t h}$ was considered. For this analysis, the PM-assisted SynRM drive was connected to a $16 \mathrm{kWh}$ battery. An ideal battery model was implemented. The loss and efficiency analysis for each case study was performed by calculating the loss energies produced during a single UDC, and extrapolated for hypothetical continuous urban driving of the light-duty electric vehicle.

Figure 13 shows the torque and speed profiles obtained in simulation under the UDC when no HFI is injected. Additionally, figure 14 shows the performance of stator current regulation under the UDC. As can be seen from figures 13 and 14, the performance of the control algorithm was as desired, as the electromagnetic torque of the machine followed the reference torque set point. In addition, figure 15(a) shows the additional current ripples introduced when the high frequency perturbation was applied for $V_{i}=60 \mathrm{~V}$ and $\omega_{t h}=800 \mathrm{rpm}$. Note that the apparent HFI ripple behavior shown in figure 15(a) (at the beginning of the simulation) was a consequence of the aliasing process that occurred as control samples were captured at a low sampling ratio.

It was confirmed from the results of the simulation that small variations in the determination of an optimal $\omega_{t h}$ under real driving conditions can be neglected. The vehicle accelerates from standstill to speeds higher than $\omega_{t h}$ within a few seconds, within a limited operational interval. For example, a theoretical improvement in autonomy in the order of $0.01 \%$ was verified by simulation for $V_{i}=60 \mathrm{~V}$
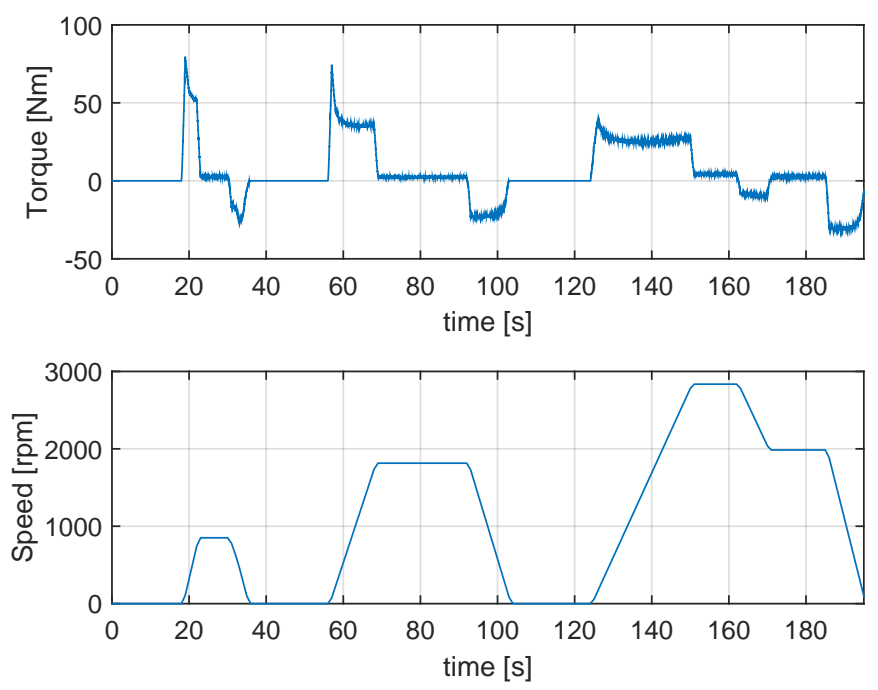

Figure 13: Torque and speed profiles obtained for a single UDC when no HFI is carried out.

when $\omega_{t h}$ was reduced from $800 \mathrm{rpm}$ to $400 \mathrm{rpm}$. Hence, further simulations were focused on the contribution of $V_{i}$ to drive losses and efficiency.

Table 4 shows the battery energy consumption $\left(E_{\text {batt }}\right)$, motor and inverter energy losses $\left(E_{\text {loss,mot }}\right.$ and $\left.E_{l o s s, i n v}\right)$, and motor, inverter, and drive efficiencies $\left(\eta_{m o t}, \eta_{i n v}\right.$ and $\left.\eta_{\text {driv }}\right)$, theoretical autonomy and autonomy reduction results for all of the cases under study. As can be seen from these results, an autonomy reduction of $0.74 \%$ was predicted by simulation when the HFI operation conditions specified by the experimental results, i.e., $V_{i}=60 \mathrm{~V}$ and $\omega_{t h}=800 \mathrm{rpm}$, were applied. However, a significant power loss reduction was achieved when minimizing HFI $(0.21 \%$ of autonomy reduction for $V_{i}=20$ ). Similarly, an evaluation of the power losses caused by the HFI was evaluated under the Urban Dynamometer Driving Schedule (UDDS), where an autonomy reduction of $0.26 \%$ was obtained for $V_{i}=60$. The impact of the additional HFI losses in this driving cycle was lower than in the UDC, as the injection time during UDDS is significantly more limited.

HFI sensorless techniques have generally been considered as a source of additional system losses [32-34]. However, this work has demonstrated that, considering an efficient electric machine design that provides reduced iron losses, the efficiency reduction in the electric machine due to HFI is very low. Additionally, if a start/stop control strategy is included in the EV control unit which deactivates the HFI when the drive is at standstill, power losses are greatly minimized (table 4). Figure 15 (b) shows how the current ripple due to HFI is reduced using this approach. Additional power losses are minimized using the start/stop control strategy, which obtain a negligible reduction of autonomy of around $0.03 \%$. Thus, following these guidelines, an HFI based sensorless strategy is, from the point of view of efficiency, feasible for an EV applica- 
Table 4: Energy and efficiency results for various HFI voltage injection conditions when a single standarized UDC is applied, with $\omega_{t h}=$ $800 \mathrm{rpm}$, including vehicle autonomy extrapolated results under continuous hypothetical vehicle urban driving for a battery with a capacity of $16 \mathrm{kWh}$.

\begin{tabular}{|lc|ccccc|}
\multicolumn{1}{c}{} & \multicolumn{5}{c|}{ Test } & number \\
\hline Parameter & Units & $\mathbf{1}$ & $\mathbf{2}$ & $\mathbf{3}$ & $\mathbf{4}$ & $\mathbf{5}$ \\
\hline $\mathbf{V}_{\mathbf{i}}$ & $\mathrm{V}$ & 0 & 20 & 40 & 60 & 60 with start/stop \\
\hline $\mathbf{E}_{\text {loss,mot }}$ & $\mathrm{J}$ & 12796 & 12804 & 12828 & 12867 & 12823 \\
$\mathbf{E}_{\text {loss,Cu }}$ & $\mathrm{J}$ & 12421 & 12428 & 12451 & 12489 & 12447 \\
$\mathbf{E}_{\text {loss,Fe }}$ & $\mathrm{J}$ & 374 & 376 & 377 & 379 & 376 \\
\hline $\mathbf{E}_{\text {loss,inv }}$ & $\mathrm{J}$ & 31609 & 31926 & 32319 & 32708 & 31625 \\
$\mathbf{E}_{\text {loss,condQ }}$ & $\mathrm{J}$ & 7117 & 7178 & 7251 & 7323 & 7126 \\
$\mathbf{E}_{\text {loss,swQ }}$ & $\mathrm{J}$ & 12130 & 12265 & 12430 & 12591 & 12133 \\
$\mathbf{E}_{\text {loss,condD }}$ & $\mathrm{J}$ & 7866 & 7943 & 8046 & 8149 & 7876 \\
$\mathbf{E}_{\text {loss,swD }}$ & $\mathrm{J}$ & 4494 & 4540 & 4593 & 4645 & 4490 \\
\hline$\eta_{\mathbf{m o t}}$ & $\%$ & 95.3 & 95.3 & 95.29 & 95.28 & 95.29 \\
$\eta_{\text {inv }}$ & $\%$ & 89.14 & 89.04 & 88.92 & 88.8 & 89.14 \\
$\eta_{\text {driv }}$ & $\%$ & 89.95 & 84.86 & 84.74 & 84.61 & 84.93 \\
Autonomy & $\mathrm{\%}$ & 365.42 & 364.66 & 363.7 & 362.71 & 365.32 \\
Autonomy reduction & $\%$ & - & 0.21 & 0.47 & 0.74 & 0.03 \\
\hline
\end{tabular}
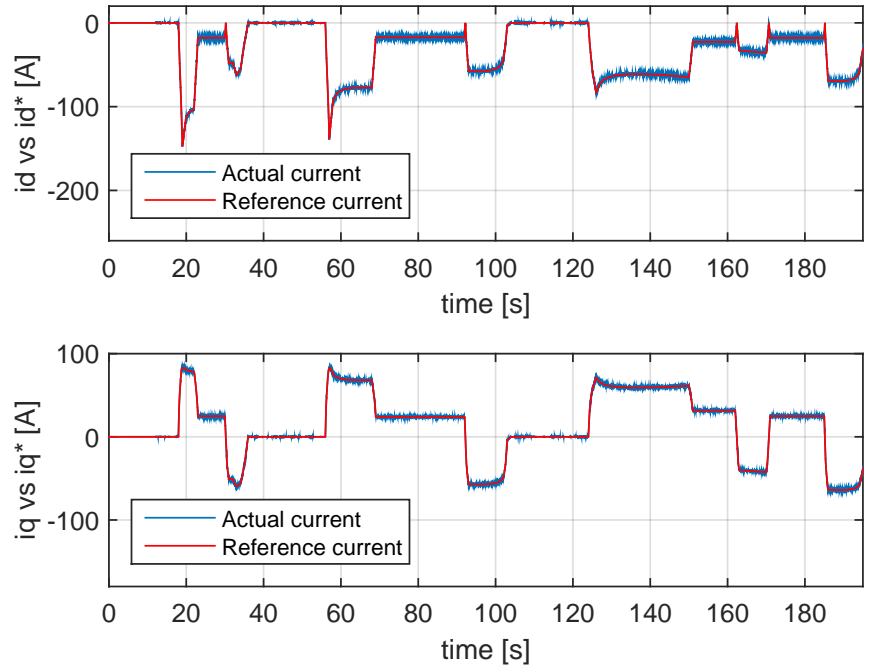

Figure 14: $i_{d}$ and $i_{q}$ regulation obtained for a single UDC when no HFI is carried out.

tion.

\section{Conclusions}

As has been experimentally demonstrated, the proposed sensorless control algorithm has supplied correct position estimation and reliable torque regulation across a wide EV operating range. However, this is achieved at the cost of increasing the power losses of the drive. The impact of HFI based EV drive sensorless control was analyzed in terms of power losses, efficiency, and autonomy throughout a real automotive driving cycle. As HFI operates at low speeds and standstill, the standardized ECE-15 UDC driving cycle was used to perform the analysis. The following conclusions can be highlighted:

1) From this study, it becomes clear that the main additional loss contribution in urban driving occurs when

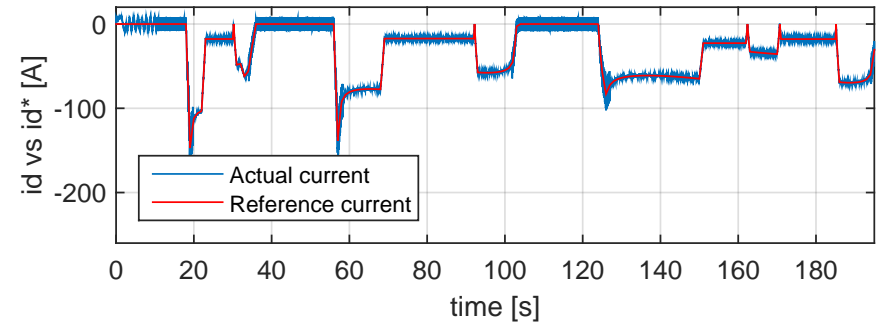

(a) $i_{d}$ current regulation with $V_{i}=60 \mathrm{~V}$.

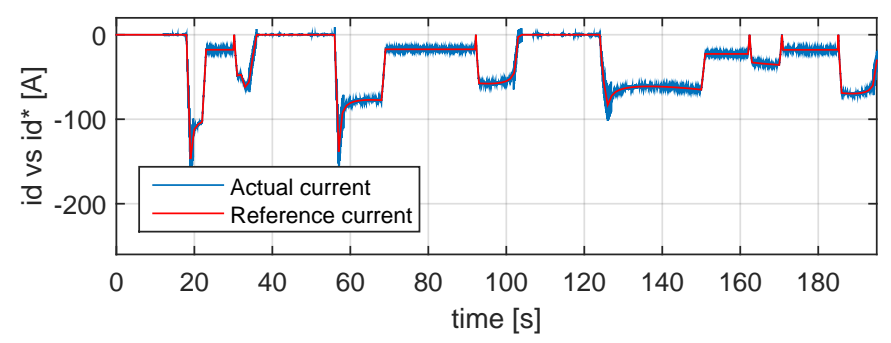

(b) $i_{d}$ current regulation with $V_{i}=60 \mathrm{~V}$, including start/stop algorithm.

Figure 15: Comparison of $i_{d}$ current regulation under HFI $\left(V_{i}=\right.$ $60 \mathrm{~V}$ ) with and without start/stop control.

the vehicle is at standstill. From an efficient sensorless drive design point of view, a start/stop procedure that interrupts HFI during standstill should be mandatory.

2) It can be concluded that the influence of the parameter $\omega_{t h}$ is minor. If an appropriate start/stop procedure is followed, the operational time in the $\left(0, \omega_{t h}\right)$ speed range of the vehicle is limited. Thus, this aspect will not prevent the use of sensorless control in low PM-flux machines, such as PM-assisted SynRMs.

3) It becomes clear that the HFI voltage amplitude 
must be minimized, in order to reduce the impact of the sensorless strategy in the drive efficiency and vehicle autonomy. Thus, machines with high saliency that facilitate HFI sensors are preferred. However, the experimental results have shown that relatively high injection voltage levels are required in some real applications, due to the operation of the drives in noisy environments.

4) As it is a high frequency perturbation, its impact on the core losses can be great. For sensorless EV drives, special attention should be lent to design aspects of the electric machine, in order to minimize the aforementioned losses.

The simulation and experimental results obtained for the proposed sensorless control approach are promising. However, extensive tests (including tests in real EV) will have to be conducted to move towards any industrialization of the proposed solution. Additionally, the impact of the HFI on the mechanical elements of the powertrain (possible degradation of the mechanical elements) should also be studied. Likewise, in the interests of driver and passenger comfort, the additional acoustic noise produced by the HFI should be quantified and considered in the vehicle design. This additional noise, if significant outside the vehicle, could be exploited to improve the safety of pedestrians.

\section{Acknowledgements}

The present work has been supported by the Government of Spain through Projects DPI2017-85404-P and DPI2014-53685-C2-2-R of the Ministerio de Economía $y$ Competitividad, through Project 2017 SGR 872 of the Generalitat de Catalunya, and through Project KT4eTRANS (KK-2015/00047 and KK-2016/00061) and GANICS (KK2017/00050), within the ELKARTEK program of the Government of the Basque Country.

This research has been conducted within the Research and Education Unit UFI11/16 of the UPV/EHU and has received funding from the Basque Government directed at research groups in the Basque government through the Department of Education, Linguistic Policy and Culture.

\section{Bibliography}

[1] C. Capasso, O. Veneri, Experimental analysis on the performance of lithium based batteries for road full electric and hybrid vehicles, Applied Energy 136 (2014) 921-930.

[2] Z. Wei, J. Xu, D. Halim, HEV power management control strategy for urban driving, Applied Energy 194 (2017) 705-714.

[3] J. González Palencia, Y. Otsuka, M. Araki, S. Shiga, Scenario analysis of lightweight and electric-drive vehicle market penetration in the long-term and impact on the light-duty vehicle fleet, Applied Energy 204 (2017) 1444-1462.

[4] E. Moreira, A. Rodrigues, J. Sodré, Analysis of CO2 emissions and techno-economic feasibility of an electric commercial vehicle, Applied Energy 193 (2017) 297-307.
[5] Y. Wang, W. Shi, B. Wang, C. Chu, R. Gadh, Optimal operation of stationary and mobile batteries in distribution grids, Applied Energy 190 (2017) 1289-1301.

[6] Global EV outlook, beyond on million electric cars, Tech. rep., International Energy Agency (2017).

[7] K. Palmer, J. Tate, Z. Wadud, J. Nellthorp, Total cost of ownership and market share for hybrid and electric vehicles in the UK, US and Japan, Applied Energy 209 (2018) 108-119.

[8] X. Ding, H. Guo, R. Xioung, F. Chen, D. Zhang, C. Gerada, A new strategy of efficiency enhancement for traction systems in electric vehicles, Applied Energy 205 (2017) 880-891.

[9] O. Veneri, C. Capasso, E. Patalano, Experimental study on the performance of a ZEBRA battery based propulsion system for urban commercial vehicles, Applied Energy 185 (2) (2017) 2005-2018.

[10] S. Chakrabortya, E. Kellerb, A. Rayb, J. Mayerb, Detection and estimation of demagnetization faults in permanent magnet synchronous motors, Electric Power System Research 96 (2013) $225-236$.

[11] S. Rezvanizaniani, Z. Liu, Y. Chen, J. Lee, Review and recent advances in battery health monitoring and prognostics technologies for electric vehicle (EV) safety and mobility, Journal of Power Sources 256 (2014) 110-124.

[12] J. Miller, D. Howell, The EV everywhere grand challenge, in: Proc. of the EVS27 International Battery, Hybrid and Fuel Cell Electric Vehicle Symposium, 2013, pp. 1-6.

[13] T. Finken, M. Hombitzer, K. Hameyer, Study and comparison of several permanent-magnet excited rotor types regarding their applicability in electric vehicles, in: Proc. of Emobility - Electrical Power Train Conference, 2010, pp. 1-7.

[14] C. Olivieri, M. Tursini, A novel PLL scheme for a sensorless PMSM drive overcoming common speed reversal problems, in: Proc. of the International Symposium on Power Electronics, Electrical Drives, Automation and Motion, 2012, pp. 10511056.

[15] E. Trancho, E. Ibarra, A. Arias, I. Kortabarria, J. Jurgens, L. Marengo, A. Fricasse, J. Gragger, PM-assisted synchronous reluctance machine flux weakening control for $\mathrm{EV}$ and $\mathrm{HEV}$ applications, IEEE Transactions on Industrial Electronics 65 (4) (2018) 2986-2995.

[16] Z. Qiao, T. Shi, Y. Wang, Y. Yan, C. Xia, X. He, New slidingmode observer for position sensorless control of permanentmagnet synchronous motor, IEEE Transactions on Industrial Electronics 60 (2) (2013) 710-719.

[17] Y. Lee, Y. Kwon, S. Sul, Comparison of rotor position estimation performance in fundamental-model-based sensorless control of PMSM, in: Proc. of the IEEE Energy Conversion Congress and Exposition (ECCE), 2015, pp. 5624-5633.

[18] S. Bolognani, L. Tubiana, M. Zigliotto, Extended Kalman filter tuning in sensorless PMSM drives, IEEE Transactions on Industry Applications 39 (6) (2003) 1741-1747.

[19] D. Janiszewski, Extended Kalman Filter Based Speed Sensorless PMSM Control with Load Reconstruction, INTECH, 2010, Kalman Filter, Chap. 8, pp. 145-160.

[20] M. Huang, A. Moses, F. Anayi, The comparison of sensorless estimation techniques for PMSM between Extended Kalman Filter and Flux-linkage Observer, in: Proc. of the Applied Power Electronics Conference and Exposition (APEC), 2006, pp. 654659.

[21] N. Henwood, J. Malaiz, L. Plary, A robust nonlinear Luenberger Observer for the sensorless control of SM-PMSM: Rotor position and magnets flux estimation, in: Proc. of the IEEE Industrial Electronics Society Conference (IECON), 2012, pp. 1625-1630.

[22] M. Jouili, K. Jarray, Y. Koubaa, M. Boussak, A Luenberger State Observer for simultaneous estimation of speed and rotor resistance in sensorless indirect stator flux orientation control of induction motor drive, in: Proc. of the International Conference on Sciences and Techniques of Automatic Control and Computer Engineering (STA), 2011, pp. 898-904.

[23] R. Li, G. Zhao, Position sensorless control for PMSM using sliding mode observer and phase-locked loop, in: Proc. of the 
Power Electronics and Motion Control Conference (IPEMC), 2009, pp. 1867-1870.

[24] H. Kim, J. Son, J. Lee, A high-speed sliding-mode observer for the sensorless speed control of a PMSM, IEEE Transactions on Industrial Electronics 58 (9) (2011) 4069-4077.

[25] E. Dehghan-Azad, S. Gadoue, D. Atkinson, H. Slater, P. Barrass, F. Blaabjerg, Sensorless control of IM for limp-home mode EV applications, IEEE Transactions on Power Electronics 32 (9) (2017) 7140-7150.

[26] G. El-Murr, D. Giaouris, J. Finch, Universal PLL strategy for sensorless speed and position estimation of PMSM, in: Proc. of the IEEE Industrial and Information Systems Conference, 2008, pp. 1-6.

[27] A. Arias, G. Asher, M. Sumner, P. Wheeler, L. Empringham, C. Silva, High frequency voltage injection for the sensorless control of permanent magnet synchronous motors using matrix converters, in: Proc. of the IEEE Industrial Electronics Society Conference (IECON), 2004, pp. 696-975.

$28]$ I. Omrane, W. Dib, E. Etien, O. Bachelier, Sensorless control of PMSM based on a nonlinear observer and a high-frequency signal injection for automotive applications, in: Proc. of the IEEE Industrial Electronics Society Conference (IECON), 2013, pp. 3130-3135.

[29] R. Leidhold, Position sensorless control of PM synchronous motors based on zero-sequence carrier injection, IEEE Transactions on Industrial Electronics 58 (12) (2011) 5371-5379.

[30] M. Coley, M. Lorenz, Rotor position and velocity estimation for a salient-pole permanent magnet synchronous machine at standstill and high speeds, IEEE Transactions on Industrial Applications 34 (4) (1998) 784-789.

[31] B. Liu, B. Zhou, J. Wei, H. Liu, J. Li, L. Wang, A rotor initial position estimation method for sensorless control of SPMSM, in: Proc. of the IEEE Industrial Electronics Society Conference (IECON), 2014, pp. 354-359.

32] C. Silva, G. Asher, M. Summer, Hybrid rotor position observer for wide speed-range sensorless PM motor drives including zero speed, IEEE Transactions on Industrial Electronics 53 (2) (2006) 373-378.

[33] L. Medjmadj, D. Diallo, M. Mostefai, C. Delpha, A. Arias, PMSM drive position estimation: Contribution to the highfrequency injection voltage selection issue, IEEE Transactions on Energy Conversion 30 (1) (2015) 349-358.

[34] A. Arias, C. Ortega, J. Zaragoza, J. Espina, J. Pou, Hybrid sensorless permanent magnet synchronous machine four quadrant drive based on direct matrix converter, International Journal of Electrical Power \& Energy Systems 45 (1) (2012) 78-86.

[35] J. Ko, D. Jin, W. Jang, C. Myung, S. Kwon, S. Park, Comparative investigation of NOx emission characteristics from a Euro 6 -compliant diesel passenger car over the NEDC and WLTC at various ambient temperatures, Applied Energy 187 (2017) $652-662$.

[36] S. Tsiakmakis, G. Fontaras, B. Ciuffo, Z. Samaras, A simulation-based methodology for quantifying european passenger car fleet CO2 emissions, Applied Energy 199 (2017) 447-465.

[37] A. Susperregui, M. Martinez, I. Zubia, G. Tapia, Design and tuning of fixed-switching-frequency second-order sliding-mode controller for doubly fed induction generator power control, IET Electric Power Applications 6 (2012) 696-706.

[38] A. Levant, Sliding order and sliding accuracy in sliding mode control, International Journal of Control 58 (6) (1993) 12471263.

[39] S. Jung, J. Hong, K. Nam, Current minimizing torque control of the IPMSM using Ferrari's method, IEEE Transactions on Power Electronics 28 (12) (2013) 5603-5617.
[40] S. Morimoto, Y. Takeda, T. Hirasa, K. Taniguchi, Expansion of operating limits for permanent magnet morot by current vector control considering inverter capacity, IEEE Transactions on Industry Applications 26 (5) (1990) 866-871.

[41] L. Lu, B. Aslan, L. Kobylanski, P. Sandulescu, F. Meinguet, X. Kestelyn, E. Semail, Computation of optimal current references for flux-weakening of multi-phase synchronous machines, in: Proc. of the Industrial Electronics Society Conference (IECON), 2012, pp. 3610-3615.

[42] S. Sul, Y. Kwon, Y. Lee, Sensorless control of IPMSM for last 10 years and next 5 years, CES Transactions on electrical machines and systems 1 (2) (2017) 91-99.

43] E. Trancho, E. Ibarra, A. Arias, C. Salazar, A. López, I. Díaz de Guereñu, A. Peña, A novel PMSM hybrid sensorless control strategy for EV applications based on PLL and HFI, in: Proc. of the IEEE Industrial Electronics Society Conference (IECON), 2016, pp. 6669-6674.

[44] S. Shue, C. Pan, Voltage-constraint-tracking-based fieldweakening control of IPM synchronous motor drives, IEEE Transactions on Industrial Electronics 55 (1) (2008) 340-347.

[45] W. Peters, O. Wallsccheid, J. Bockere, A precise open-loop torque control for an interior permanent magnet synchronous motor (IPMSM) considering iron losses, in: Proc. of the IEEE Industrial Electronics Society Conference (IECON), 2012, pp. $2877-2882$.

[46] F. Fernandez Bernal, A. Garcia Cerrada, R. Faure, Detemination of parameters in interior permanent-magnet synchronous motors with iron losses without torque measurement, IEEE Transactions on Industry Applications 37 (5) (2001) 1265-1272.

[47] S. Morimoto, Y. Takeda, T. Hirasa, Loss minimization control of permanent magnet synchronous motor drives, IEEE Transactions on Industrial Electronics 41 (5) (1994) 511-517.

[48] F. Fernandez Bernal, A. Garcia Cerrada, R. Faure, Model-based loss minimization for $\mathrm{DC}$ and $\mathrm{AC}$ vector-controlled motors including core saturation, IEEE Transactions on Industry Applications 36 (3) (2000) 755-763

[49] C. Xi, H. Shenghua, L. Bingzhang, X. Yangxiao, Losses and thermal calculation of IGBT and FWD in PWM inverter for electric engineering maintenance rolling stock, in: Proc. of the International Conference on Electrical Machines and Systems (ICEMS), 2016.

[50] Y. Gerstenmainer, W. Kiffe, G. Wachutka, Combination of thermal subsystems modeled by rapid circuit transformation, in: Proc. of the 13th International Workshop on Thermal Investigation of ICs and Systems (THERMINIC), 2007, pp. 115-120.

[51] D. Tsokolis, S. Tsiakmakis, A. Dimaratos, G. Fontaras, P. Pistikopoulos, B. Ciuffo, Z. Samaras, Fuel consumption and $\mathrm{CO} 2$ emissions of passenger cars over the new worldwide harmonized test protocol, Applied Energy 179 (2016) 1152-1165.

[52] H. Wang, W. Zhang, M. Ouyang, Energy consumption of electric vehicles based on real-world driving patterns: A case study of Beijing, Applied Energy 157 (2015) 710-719.

[53] L. Chen, J. Wang, P. Lazari, X. Chen, Optimizations of a permanent magnet machine targeting different driving cycles for electric vehicles, in: Proc. of the IEEE International Electric Machines \& Drives Conference (IEMDC), 2013, pp. 855-862.

[54] D. Maksimovic, A. Stankovic, V. Thottuvelil, G. Verghese, Modeling and simulation of power electronics converters, Proceedings of the IEEE 86 (6) (2001) 898-912.

[55] E. Ibarra, I. Kortabarria, J. Andreu, I. Martínez de Alegría, J. Martin, P. Ibañez, Improvement of the design process of matrix converter platforms using the switching state matrix averaging simulation method, IEEE Transactions on Industrial Electronics 59 (1) (2011) 220-234. 